\title{
Fetal Hippocampal Grafts Containing CA3 Cells Restore Host Hippocampal Glutamate Decarboxylase-Positive Interneuron Numbers in a Rat Model of Temporal Lobe Epilepsy
}

\author{
Ashok K. Shetty and Dennis A. Turner \\ Departments of Surgery (Neurosurgery) and Neurobiology, Duke University Medical Center. Durham, North Carolina \\ 27710, and Medical Research and Surgery (Neurosurgery) Services, Veterans Affairs Medical Center, Durham, North \\ Carolina 27705
}

\begin{abstract}
Degeneration of CA3-pyramidal neurons in hippocampus after intracerebroventricular kainic acid (KA) administration, a model of temporal lobe epilepsy, results in hyperexcitability within both dentate gyrus and the CA1 subfield. It also leads to persistent reductions in hippocampal glutamate decarboxylase (GAD) interneuron numbers without diminution in Nissl-stained interneuron numbers, indicating loss of GAD expression in a majority of interneurons. We hypothesize that enduring loss of GAD expression in hippocampal interneurons after intracerebroventricular $\mathrm{KA}$ is attributable to degeneration of their CA3 afferent input; therefore, fetal CA3 grafts can restore GAD interneuron numbers through graft axon reinnervation of the host. We analyzed GAD interneuron density in the adult rat hippocampus at 6 months after KA administration after grafting of fetal mixed hippocampal, CA3 or CA1 cells into the CA3 region at $45 \mathrm{~d}$ after lesion, in comparison with "lesion-only" and intact hippocampus. In dentate and CA1 regions of the lesioned hippocampus receiving grafts of either mixed hippocampal or CA3 cells, GAD interneu-
\end{abstract}

ron density was both significantly greater than lesion-only hippocampus and comparable with the intact hippocampus. In the CA3 region, GAD interneuron density was significantly greater than lesion-only hippocampus but less than the intact hippocampus. Collectively, the overall GAD interneuron density in the lesioned hippocampus receiving either mixed hippocampal or CA3 grafts was restored to that in the intact hippocampus. In contrast, GADinterneuron density in the lesioned hippocampus receiving CA1 grafts remained comparable with lesion-only hippocampus. Thus, grafts containing CA3 cells restore CA3 lesioninduced depletions in hippocampal GAD interneurons, likely by reinnervation of GAD-deficient interneurons. This specific graftmediated effect is beneficial because reactivation of interneurons could ameliorate both loss of functional inhibition and hyperexcitability in CA3-lesioned hippocampus.

Key words: brain injury; GAD-67; hippocampus; neural grafting; nonpyramidal neurons; temporal lobe epilepsy
Grafting of specific fetal neural cells has shown promise in ameliorating symptoms of Parkinson's and Huntington's diseases (Dunnett et al., 1997; Kordower et al., 1998). Animal studies have shown that grafting of appropriate fetal cells leads to functional replacement of lost cells and partial restoration of disrupted synapses (Isacson and Deacon, 1997; Sanberg et al., 1997; Palfi et al., 1998). The potential of neural grafting for treating hippocampal diseases is also being explored (Woodruff et al., 1987, 1992; Onifer and Low, 1990; Tonder et al., 1990; Mudrick and Baimbridge, 1991; Granholm et al., 1995; Shetty and Turner, 1996; Tarricone et al., 1996). Temporal lobe epilepsy (TLE) is one of the hippocampal diseases for which specific cell grafting may be beneficial for ameliorating hyperexcitability. The hypothesis for graft-mediated suppression of hyperexcitability is that circuitry restoration within hippocampus by appropriate grafts leads to afferent control over autonomous regions to reduce their seizure-generating output into the CNS.

Intracerebroventricular kainic acid (KA) administration in rat, a model for studying TLE and hyperexcitability, results in the degeneration of CA3 pyramidal and hilar neurons. This leads to reorganization of circuitry and hyperexcitability in CA1 and dentate regions (Nadler et al., 1980a,b; Turner and Wheal, 1991a,b; Shetty and Turner, 1996, 1999a,b). Although the hyperexcitability

\footnotetext{
Received June 19, 2000; revised Aug. 31, 2000; accepted Sept. 19, 2000.

This work was supported by National Institute of Neurological Disorders and Stroke Grant RO1 NS36741 (A.K.S.) and Department of Veterans Affairs Merit Review Award (A.K.S.). We thank Yolanda Phillips for technical help and Toni Shaw for secretarial assistance.

Correspondence should be addressed to Dr. Ashok K. Shetty, Division of Neurosurgery, Box 3807, Duke University Medical Center, Durham, NC 27710. E-mail: Ashok.Shetty@Duke.Edu.

Copyright (C) 2000 Society for Neuroscience $0270-6474 / 00 / 208788-14 \$ 15.00 / 0$
}

is associated with a sustained loss of functional inhibition (Cornish and Wheal, 1989; Perez et al., 1996), the issue of interneuron loss remains controversial, as in other models of TLE and the human situation (Sloviter, 1987, 1991; Franck et al., 1988; Davenport et al., 1990; Houser, 1991; Obenaus et al., 1993; Mathern et al., 1995; Shetty and Turner, 1995a; Houser and Esclapez, 1996; Dudek and Spitz, 1997; Esclapez et al., 1997; Rempe et al., 1997; Williamson et al., 1999). However, a recent study at 1-6 months after KA reveals persistent reductions in hippocampal glutamate decarboxylase (GAD)-positive interneuron numbers without a comparable diminution in Nissl-stained interneuron numbers (Shetty and Turner, 1999c, 2000), indicating a sustained loss of GAD expression in a major fraction of interneurons after intracerebroventricular KA. Thus, there could be a direct link between the loss of functional inhibition and reductions in GAD-positive interneuron numbers. Therefore, strategies that restore GAD interneuron numbers to levels observed in intact hippocampus may be beneficial for both restoring the functional inhibition and ameliorating hyperexcitability.

We hypothesize that enduring loss of GAD expression in hippocampal interneurons after intracerebroventricular KA is attributable to degeneration of their CA3 afferent input; therefore, transplantation of fetal CA3 grafts can restore GAD interneuron numbers by providing specific afferent control from graft axons extending into the host. Grafts containing CA3 cells placed into the lesioned CA3 region exhibit excellent survival and specific efferent projections and can suppress aberrant mossy fiber sprouting (Shetty and Turner, 1995b, 1997a,b; Shetty et al., 2000; Zaman et al., 2000). In this study, we compared the effect of three different fetal grafts (mixed hippocampus, CA3, and CA1) on GAD interneuron density in the lesioned adult hippocampus. Grafts were placed into the lesioned CA3 region at $45 \mathrm{~d}$ after $\mathrm{KA}$ administration, and 
GAD interneuron density was measured 6 months after lesion, in comparison with "lesion-only" and intact hippocampus.

\section{MATERIALS AND METHODS}

Kainic acid lesions. Unilateral intracerebroventricular KA administration was performed on adult male Fischer 344 rats (4-6 months old; HarlanSprague Dawley, Indianapolis, IN), using methods detailed elsewhere (Lancaster and Wheal, 1982; Shetty and Turner, 1995a, 1996, 1997a,b). These protocols have been approved by the Duke University Institutional Animal Care and Use Committee. In brief, rats were anesthetized with a mixture containing ketamine $(50 \mathrm{mg} / \mathrm{ml})$, xylazine $(6 \mathrm{mg} / \mathrm{ml})$, and acepromazine $(0.5 \mathrm{mg} / \mathrm{ml})$ at a dose of $1.25 \mathrm{ml} / \mathrm{kg}$ body weight. After this, each rat was fixed into a stereotaxic apparatus, the incisor bars were set at $3.7 \mathrm{~mm}$ below the interaural line, and the dorsal surface of the skull was exposed. A burr hole was drilled in the skull using the following stereotaxic coordinates: anteroposterior, $3.7 \mathrm{~mm}$ caudal to bregma; and lateral, 4.1 $\mathrm{mm}$ right lateral to the midline. A $10 \mu \mathrm{l}$ Hamilton (Reno, NV) syringe fitted with a $25 \mathrm{G}$ needle and filled with KA solution in saline was placed over the burr hole and lowered $4.5 \mathrm{~mm}$ below the surface of the brain, an $1 \mu \mathrm{l}$ of KA $(0.5 \mu \mathrm{g})$ was injected at a rate of $0.2 \mu \mathrm{l} / \mathrm{min}$. The needle was left in place for $15 \mathrm{~min}$ before slowly being retracted.

Collection of mixed hippocampal, CA3, and CA1 tissues from E19 rat fetuses. Fetuses were removed from deeply anesthetized pregnant rats by cesarean section and collected in a Petri plate containing calcium- and magnesium-free HBSS (Sigma, St. Louis, MO) with $0.6 \%$ glucose, $10 \mathrm{mM}$ HEPES and $1 \%$ penicillin-streptomycin, and the brains were dissected under an operating microscope. The dissection of whole hippocampus for mixed hippocampal cell preparation was performed as detailed elsewhere (Shetty and Turner, 1995b). For dissection of CA3 and CA1 tissues, each cerebral hemisphere was separated from the brainstem and cut coronally into four slices of equal size, and slices containing hippocampal tissue were identified under a dissection microscope. The middle two slices from each hemisphere were consistently found to contain hippocampal tissues. From each of these pieces, hippocampal tissue was unfolded, and subfields CA3 (lateral most part of hippocampus with choroid plexus) and CA1 (medial part of hippocampus adjoining subiculum) were separated by sharp cuts using scalpel blade and collected separately in fresh HBSS (Zaman et al., 2000). The CA1 tissue collected this way also contained primordial dentate gyrus, because the tiny area of primordial dentate gyrus could not be separated by the above procedure.

Preparation of cell suspension from whole hippocampal, CA3, and CA1 tissues. After dissection, whole hippocampal, CA3, and CA1 tissues were processed separately for dissociation and preparation of single-cell suspension using mechanical trituration. Using a fine-polished Pasteur pipette, tissue pieces were triturated 30 times in $2 \mathrm{ml}$ of HBSS, and the resulting cell suspension was diluted with $10 \mathrm{ml}$ of fresh HBSS. The diluted cell suspension was then sieved through a steel mesh (pore size, $175 \mu \mathrm{m}$ ) and centrifuged at $800 \mathrm{rpm}$ for $8 \mathrm{~min}$, and the pellet was resuspended in HBSS Cells were washed twice by resuspension in HBSS and centrif ugation. The final pellet was resuspended in $30 \mu \mathrm{l}$ of HBSS, and viability was assessed using the trypan blue exclusion method. The density of cells was then adjusted to $1 \times 10^{5}$ viable cells/ $\mu 1$ and stored on ice.

Transplantation. Kainic acid-lesioned rats, at $45 \mathrm{~d}$ after lesion, were anesthetized and fixed into a stereotaxic apparatus. The plane of the incisor bar was set at $3.3+0.3 \mathrm{~mm}$ below the interaural line. The detailed transplantation procedure is described elsewhere (Shetty and Turner, 1995b). One microliter of cell suspension containing 100,000 live cells was injected into each of the following two locations in the hippocampus ipsilateral to the KA lesion: (1) anteroposterior (AP), $3.3 \mathrm{~mm}$ posterior to bregma; lateral (L), $2.5 \mathrm{~mm}$ right lateral to midline; and ventral (V), 3.5 $\mathrm{mm}$ from the surface of brain; and (2) AP, $4.3 \mathrm{~mm}$; L, $3.5 \mathrm{~mm}$ right lateral; and $\mathrm{V}, 3.5 \mathrm{~mm}$. These locations were chosen to place the grafts close to the degenerated CA3 pyramidal cell layer.

Tissue processing and selection of sections. All animals (normal control animals, KA-treated lesion-only animals at 6 months after lesion, and KA-treated and grafted animals at 6 months after lesion and 4.5 months after transplantation) were deeply anesthetized with halothane and perfused through the heart first with $200 \mathrm{ml}$ of heparinized saline (10 min) followed by $500 \mathrm{ml}$ of fixative solution $(30 \mathrm{~min})$ containing $4 \%$ paraformaldehyde in $0.1 \mathrm{M}$ phosphate buffer (PB), $\mathrm{pH}$ 7.4. The brains were removed, post-fixed in $4 \%$ paraformaldehyde for $18 \mathrm{hr}$ at $4^{\circ} \mathrm{C}$ and cryoprotected in $30 \%$ sucrose solution in PB. Cryostat sections were cut coronally through the septal or dorsal hippocampus and collected serially in PB. Twenty-micrometer-thick sections through the septal hippocampus (at levels corresponding to $2.8-4.5 \mathrm{~mm}$ posterior to bregma; Paxinos and Watson, 1986), with a distance of $100 \mu \mathrm{m}$ between them, were selected in each animal belonging to different groups and processed for quantitative immunocytochemical analysis of GAD. In lesion-only and lesioned and grafted animals, every 12 th section at the above levels of the hippocampus was also mounted and stained with cresyl violet. Nissl staining confirmed the completeness of the KA-induced lesion in lesion-only animals. In lesioned and grafted animals, Nissl staining showed both cell loss induced by the KA lesion and the location of the transplant in relation to the degenerated CA3 cell layer. The above protocol ensured that chosen sections were independent from one another to clearly avert counting of interneurons from contiguous sections and hence replication of the find- ings of the previous section. In lesioned and grafted animals, it was also ensured that the selected sections contained a transplant in the close vicinity of the degenerated CA3 cell layer. Coronal sections through the septal hippocampus, at levels specified above, were preferred over those from the temporal hippocampus because: (1) the coronal sections through the septal hippocampus have distinct CA1 and CA3 cell layers separated by a small region of the CA2 cell layer; (2) various strata in both CA1 and CA3 subfields are well demarcated in coronal sections of the septal hippocampus (Shetty and Turner, 1998); and (3) injected transplants were clearly located in the septal hippocampus.

Glutamate decarboxylase 67 immunohistochemistry. For treatment of free-floating sections in different reagents used for GAD-67 immunohistochemistry, 24-well cell culture plates were used. Sections were first rinsed in $0.1 \mathrm{M}$ PBS and incubated with $1 \%$ sodium borohydride solution in distilled water for $15 \mathrm{~min}$. Treatment with sodium borohydride diminishes both free aldehyde groups and double bonds and hence enriches immunoreactivity of protein antigens (Toth and Freund, 1992). Sections were then washed five times in $0.1 \mathrm{M}$ PBS, treated with $10 \%$ normal goat serum (for $30 \mathrm{~min}$ ), and incubated in the primary antibody solution for $48 \mathrm{hr}$ at $4^{\circ} \mathrm{C}$. The primary antibody, an isoform of GAD (GAD-67; K2 antiserum from Chemicon, Temecula, CA; Kaufman et al., 1991; Esclapez et al., 1994), was diluted to 1:2000 in a solution containing $0.1 \mathrm{M}$ PBS and 3\% normal goat serum (NGS). The GAD-67 antibody used in this study was raised in a rabbit and has been shown to recognize only GAD-67 with both Western blotting and immunohistochemistry. After incubation in the primary antibody, sections were rinsed in PBS, treated with goat anti-rabbit peroxidase (1:500 dilution in $0.1 \mathrm{~m}$ PBS containing 3\% NGS) for $2 \mathrm{hr}$, and washed in PBS, and the peroxidase reaction was developed using 3,3diaminobenzidine and nickel chloride as chromogens (Vector Laboratories, Burlingame, CA). The chromogen reaction was first standardized under the microscope in a few sections of control rats to establish the best possible duration of incubation required for dense immunostaining of the cell body of interneurons with minimal background staining. The identical period of incubation was then used for all sections belonging to different groups (control, lesion-only, and lesioned and grafted animals). Sections were mounted on gelatinized slides, dehydrated in alcohol, cleared in xylene, and coverslipped with Permount. To prevent any potential effects of the staining method on the number of GAD-67-positive interneurons, sections from all groups of animals were processed with matching concentrations of primary and secondary antibody solutions. In addition, both the number of washes between incubations and the concentration of DABhydrogen peroxide for chromogen reaction were kept constant. Some sections from control, lesion-only and lesioned and grafted KA-lesioned groups were also processed in different wells of the same plate under the same incubation conditions. Under these conditions, the overall pattern of GAD-67 immunostaining was generally similar across all groups of animals and appeared comparable with earlier reports on GAD-67 expression in the rat hippocampus (Sloviter et al., 1996; Morin et al., 1998; Shetty and Turner, 1998). Negative control sections were processed using the same protocol, except that the primary antibody treatment was replaced by continued incubation in normal goat serum. Neither immunostaining nor any recognizable background staining was observed in negative control sections. Thus, the immunostaining protocols used in this study clearly minimize effects of the staining protocol on the number of interneurons stained and are consistent with methods used in earlier quantitative immunohistochemical studies of GAD-67.

Morphometric analysis. Numerical density of GAD-67 positive interneurons per square millimeter volume of tissue $\left(N_{\mathrm{v}}\right)$ was measured separately for every layer of the dentate gyrus and CA 1 and CA3 subfields. Furthermore, to determine the overall density changes in the septal hippocampus, density per square millimeter volume of tissue was also determined for the entire dentate gyrus, CA1 and CA3 subfields, and the whole septal hippocampus. Three sections through the septal hippocampus were used for these measurements in each animal belonging to the following five groups: (1) intact control hippocampi $(n=8)$; (2) CA3-lesioned hippocampi at 6 months after intracerebroventricular KA administration $(n=6) ;(3)$ CA3-lesioned hippocampi with mixed fetal hippocampal cell grafts at 6 months after intracerebroventricular KA administration $(n=6)$; (4) CA3-lesioned hippocampi with fetal CA3 cell grafts at 6 months after intracerebroventricular KA administration $(n=6)$; and (5) CA3-lesioned hippocampi with fetal CA1 cell grafts at 6 months after intracerebroventricular KA administration $(n=6)$. For all measurements, Neurolucida brain mapping software was used, incorporating optical image superposition of the microscope field and a computer monitor (Microbrightfield, Colchester, VT; Shetty and Turner, 1995a,b, 1998). At a magnification of $160 \times$ (using a $20 \times$ objective lens and $8 \times$ eye pieces), the entire area of individual layers in the dentate gyrus (dentate hilus, granule cell layer, and molecular layer) and CA1 and CA3 subfields (strata oriens, radiatum, and pyramidale) was marked in each section with separate lines. The borders of different layers in the dentate gyrus and CA1 and CA3 subfields were established according to Paxinos and Watson (1986). However, different strata of the smaller CA2 subfield were incorporated into the corresponding strata of the CA1 subfield. Additionally, in the CA1 and CA3 subfields, the stratum lacunosum moleculare was included with the area marked for stratum radiatum, because clear demarcation between stratum radiatum and stratum lacunosum moleculare is not evident in GAD-67immunostained sections. From the area measurements of different strata in 
the dentate gyrus and CA1 and CA3 subfields, total area was calculated for each of these hippocampal regions and the entire septal hippocampus.

Then, the location of all GAD-67-positive interneurons was denoted in every stratum with discrete symbols. In all animals, pyramidal-shaped interneurons located at the junction of granule cell layer and dentate hilus (basket cells) were included with the dentate hilus. In grafted animals, GAD-67 interneurons located within the graft mass were excluded, because these interneurons are likely derived from grafts. The typical sparse distribution of GAD-67 interneurons throughout the hippocampus in $20-\mu \mathrm{m}$-thick sections permitted unambiguous detection of all GAD-67 interneurons at $160 \times$ magnification. From these measurements, density of GAD-67 interneurons per square millimeter area was calculated for all layers in every section by dividing the number of GAD-67 interneurons encountered in the individual layer by the whole area of that layer Likewise, density of GAD-67 interneurons per square millimeter area of each hippocampal subfield and the entire septal hippocampus was also determined. Because comparison of density of neurons per square millimeter area between different groups is sensitive to the tissue shrinkage, we determined the extent of shrinkage in both lesion-only hippocampus and the lesioned hippocampus with grafts, relative to the control intact hippocampus. The extent of shrinkage was determined separately for different layers of the dentate gyrus and CA1 and CA3 subfields, for the entire dentate gyrus and CA1 and CA3 subfields, and for the whole septal hippocampus. Every area measurement in both lesion-only hippocampus and the lesioned hippocampus with grafts was corrected with corresponding shrinkage factor when the extent of shrinkage was statistically significant, before calculation of the density of neurons per square millimeter area. Later, the density of GAD-67 interneurons per square millimeter area of tissue in each stratum or subfield and entire septal hippocampus was transformed to the numerical density per cubic millimeter volume of tissue $\left(N_{\mathrm{v}}\right)$ using the formula, $N_{\mathrm{v}}=N_{\mathrm{f}} /(t+d)$, where $N_{\mathrm{A}}$ is the number of neurons per square millimeter area of tissue, $t$ is the section thickness, and $d$ is the mean diameter of GAD-67 interneurons (Abercrombie, 1946). This conversion clearly provided correction for differential size of interneurons between different groups analyzed in this study.

Measurement of shrinkage in lesioned hippocampus attributable to CA3 cell loss. The extent of shrinkage in distinct strata and subfields of both lesion-only hippocampus and lesioned hippocampus with grafts was measured by comparing the area of each stratum or subfield and the entire septal hippocampus between the intact control hippocampus, the lesiononly hippocampus, and the lesioned hippocampus with grafts. For this evaluation, GAD-67-immunostained hippocampal sections nearly belonging to the same anteroposterior levels were chosen in all groups. Area measurements obtained from eight sections belonging to four different animals were used for this comparison in each group. A highly consistent length of dentate granule cell layer (range, $3.4-4.0 \mathrm{~mm}$ ) in sections across different groups established that sections chosen in different groups have come from corresponding anteroposterior levels. In lesioned hippocampus with grafts, area measurements in the CA3 region excluded the area occupied by grafts, because interneurons within grafts are likely graftderived. This analysis uncovered differential shrinkage in different layers and subfields of both lesion-only and lesioned, grafted hippocampus. Dentate gyrus of both lesion-only and lesioned, grafted hippocampus did not exhibit significant shrinkage in any of its layers; hence the different area measurements for dentate gyrus in these groups were not corrected with shrinkage factors. However, both CA1 and CA3 subfields demonstrated significant shrinkage in both lesion-only and lesioned, grafted hippocampus. The CA1 subfield, when taken as a single entity, demonstrated $32 \%$ shrinkage at 6 months after lesion $(p<0.05)$ in both lesion-only and lesioned, grafted hippocampus. Among individual layers of CA1 in lesiononly hippocampus, the stratum oriens exhibited $25 \%$ shrinkage $(p>0.05)$, and strata radiatum and pyramidale exhibited $33-36 \%$ shrinkage $(p<$
$0.05)$. In lesioned hippocampus with grafts, all three strata of the CA1 subfield exhibited significant shrinkage $(28-37 \% ; p<0.05)$. A higher level of shrinkage was evident in the CA3 subfield of both lesioned groups. In lesion-only hippocampus, the CA3 subfield as a whole exhibited $44 \%$ shrinkage $(p<0.05)$. Among individual layers, strata pyramidale and radiatum, respectively, exhibited 43 and $61 \%$ shrinkage $(p<0.01)$, whereas the stratum oriens exhibited no significant shrinkage. In lesioned hippocampus with grafts, all layers of the CA3 subfield exhibited significant shrinkage (entire subfield, $53 \%$; stratum oriens, $54 \%$; stratum radiatum, $51 \%$; stratum pyramidale, $66 \% ; p<0.01)$. Measurement of the entire septal hippocampus also showed significant shrinkage (25\% in lesion-only hippocampus and $31 \%$ in lesioned hippocampus with grafts; $p<0.05$ ). Areas of different layers, subfields, and the entire septal hippocampus in both lesion-only and lesioned and grafted groups were corrected by multiplying with appropriate shrinkage factors when the extent of shrinkage was statistically significant. This correction was accomplished before the calculation of density per square millimeter of area. The shrinkage factors applied for different layers, subfields, and entire septal hippocampus varied from 1.33 (for $25 \%$ shrinkage) to 2.94 (for $66 \%$ shrinkage).

Data analyses. Three sections $(20 \mu \mathrm{m}$ thick) were measured in every animal belonging to different groups. Because the three sections chosen for measurement in each animal were separated by a distance of $100 \mu \mathrm{m}$ between them, counting of GAD-67 interneurons from adjacent sections was avoided, and values from each section were considered independent. The total number of animals analyzed per group varied from six to eight.
The mean value for every layer in each hippocampal subfield was individually calculated for every animal, using data from three sections before the means and SEs were determined for the total number of animals included per group. Data from the control animal group $(n=8)$ were compared with each of the four lesioned groups (lesion-only animals, lesioned animals with mixed hippocampal cell grafts, lesioned animals with CA3 cell grafts, and lesioned animals with CA1 cell grafts; $n=6$ per group) using one-way ANOVA with the Student-Newman-Keuls multiple comparisons post hoc test. All data are presented as means \pm SEM.

Measurement of the size of GAD-67 interneurons. Differences in cell size between groups can lead to either overestimation or underestimation of cell density in one of the groups. Therefore, in all animal groups, we measured the mean diameter of the soma of GAD-67 interneurons in different subfields of the hippocampus and corrected all GAD-67 cell counts in different groups for cell size during the conversion from density per square millimeter area to density per cubic millimeter volume of tissue. In the dentate gyrus, interneurons were analyzed from the dentate hilus and the granule cell layer. In CA1 and CA 3 subfields, interneurons were measured from strata radiatum and pyramidale. In all groups, only well delineated GAD-immunopositive cell bodies with prominent nuclei and a minimum of one primary dendrite were chosen. The mean diameter of interneurons was measured at $800 \times$ magnification (using a $100 \times$ oil immersion objective lens) with Neurolucida (Shetty and Turner, 1998). In each of the five groups, 40 interneuron cell bodies were measured for each of the three hippocampal subfields from sections of four different animals (10 neurons per animal for every hippocampal subfield). The mean value for each subfield was separately calculated for every animal using data from 10 neurons before the means and SEs were established for the group. Data from the control animal group were compared with both lesion-only and three lesioned, grafted groups.

\section{RESULTS}

\section{Alterations in cytoarchitecture of the septal hippocampus after intracerebroventricular KA administration}

Evaluation of Nissl-stained sections at 6 months after lesion clearly confirmed degeneration of the CA3 pyramidal neurons in the hippocampus ipsilateral to the intracerebroventricular KA administration (Fig. $1 B_{1}, B_{3}$ ). The CA3 cell loss was highly consistent throughout the septotemporal axis of the hippocampus, as detailed in our recent study (Shetty and Turner, 1999a). Loss of CA3 pyramidal cells caused shrinkage either dorsoventrally or mediolaterally in the septal hippocampus of all animals belonging to different lesioned groups. However, both CA1 pyramidal cell and granule cell layers were completely spared (Fig. $1 B_{1} B_{2}$ ).

\section{Changes in distribution of Nissl-stained interneurons after intracerebroventricular KA administration}

Distribution of Nissl stained interneurons within strata oriens and radiatum of both CA1 and CA3 subfields in the lesioned hippocampus appeared similar to corresponding layers in the intact control hippocampus (Fig. $1 A_{2}, A_{3}, B_{2}, B_{3}$ ). The only exception was the CA1 stratum oriens where interneuron distribution appeared extremely sparse (Fig. $1 B_{2}$ ). Recently, changes in the density of Nissl stained interneurons within strata oriens and radiatum of CA1 and CA3 subfields after intracerebroventricular KA administration have been quantified in our laboratory at 1, 4, and 6 months after lesion time points (Shetty and Turner, 1999c, 2000; our unpublished observations). This measurement revealed no changes in the density of interneurons in these layers at all postlesion time points, except the CA1 stratum oriens at 6 months after lesion, where interneuron density was reduced by $27 \%$. This highly contrasts with GAD-67 interneurons during the same period, which shows dramatic and irreversible reductions in density throughout the CA3 lesioned hippocampus. These results suggest that the reduced GAD-67 interneuron density in the hippocampus after CA3 lesion primarily reflects a severe downregulation of GAD-67 expression in a major fraction of interneurons rather than widespread degeneration or loss of interneurons.

\section{GAD-67 interneurons in the intact hippocampus and lesion-only hippocampus at $\mathbf{6}$ months after lesion}

The pattern of GAD-67 immunostaining in the intact hippocampus and lesion-only hippocampus at 1, 4, and 6 months after lesion have been described recently for adult Fischer 344 rats (Shetty and Turner, 1998, 2000; our unpublished observations). Briefly, in the 

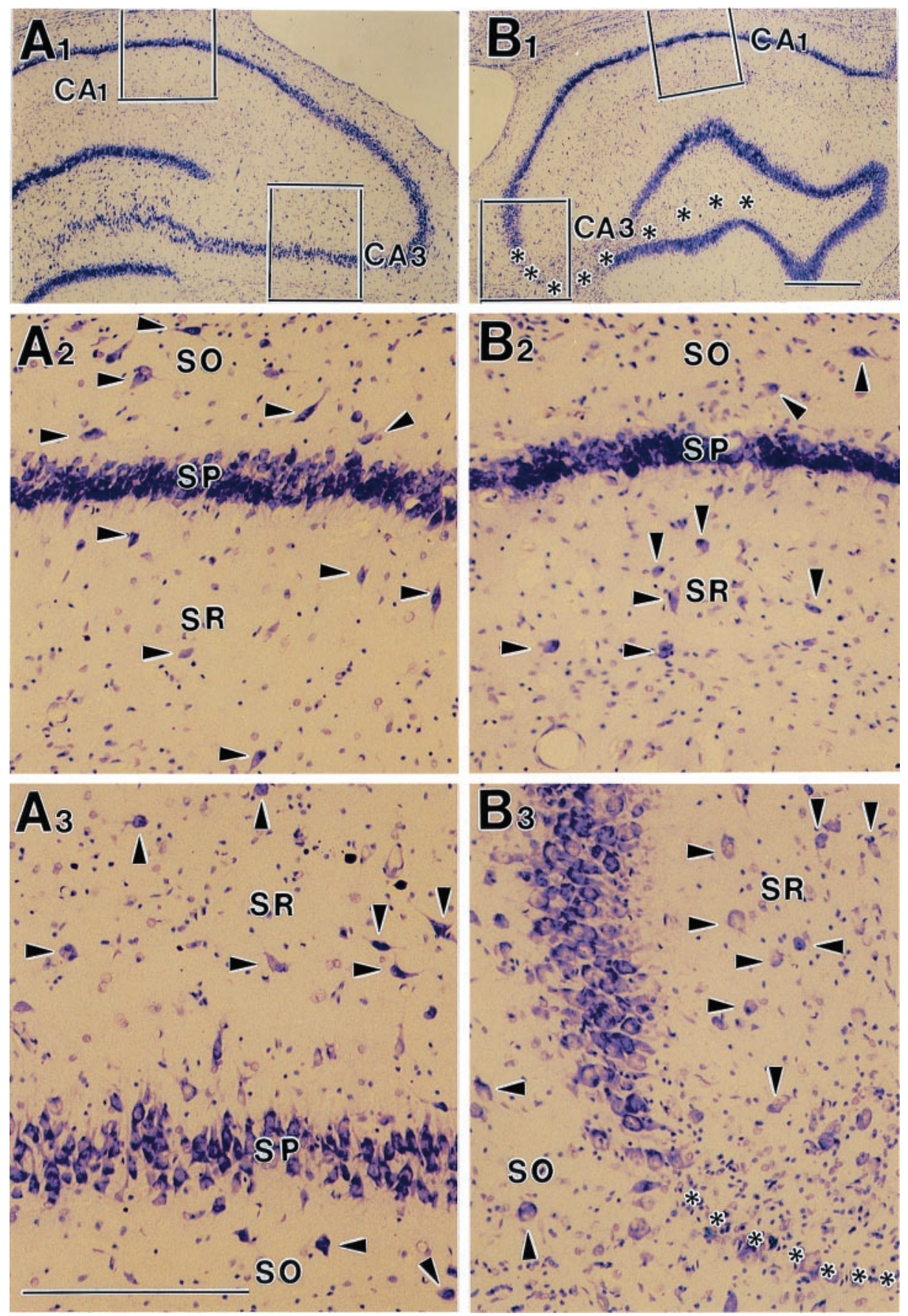

Figure 1. Nissl-stained sections of the hippocampal formation from a control rat $\left(A_{l}\right)$ and a KA-treated rat at 6 months after lesion $\left(B_{1}\right)$. Intracerebroventricular kainic acid induced CA3 pyramidal cell loss $\left(B_{1}\right.$, asterisks $)$ appears total in $\mathrm{CA} 3 \mathrm{~b}$ and $\mathrm{CA} 3 \mathrm{c}$ subregions. A2 and B2, respectively, show a magnified view of the boxed CA1 area in $A_{1}$ and $B_{1} . A_{3}, B_{3}$, Enlarged view of boxed CA3 area in $A_{1}$ and $B_{1}$. Arrowheads in $A_{2}, B_{2}, A_{3}$, and $B_{3}$ point to interneurons. Note that the distribution of interneurons in the stratum radiatum $(S R)$ of the CA1 subfield and strata oriens $(S O)$ and radiatum of the CA3 subfield appear similar between the control hippocampus and the KAlesioned hippocampus. In contrast, the stratum oriens of the CA1 subfield in KA-lesioned hippocampus exhibits a far fewer interneurons $\left(B_{2}\right)$. Asterisks in $B_{3}$ denote the degenerated CA3 cell layer. $D G$, Dentate gyrus; $S P$, stratum pyramidale. Scale bars: $A_{1}, B_{1}, 400 \mu \mathrm{m} ; A_{2}, B_{2}, A_{3}, B_{3}$, $200 \mu \mathrm{m}$. intact hippocampus, interneurons positive for GAD-67 were observed in all layers of the different subfields (Fig. 2 $A_{1}-A_{4}$ ). Both soma and proximal dendrites of interneurons exhibited dense immunoreactivity for GAD-67. GAD-67-positive interneurons were also seen in every layer of all subfields of lesion-only hippocampus (Fig. $2 B_{1}-B_{4}$ ). However, the density of GAD-67 interneurons appeared reduced in all strata of every subfield. Reductions in GAD-67 interneuron density were striking in the dentate hilus, with particular reduction noted in pyramidal-shaped basket cells at the junction of the hilus and the granule cell layer (Fig. $2 \mathrm{~B}_{2}$ ) and strata oriens and radiatum of CA1 and CA3 (Fig. $2 B_{3}, B_{4}$ ). Compared with these regions, a higher density of GAD-67 interneurons was present at the junction between strata radiatum and lacunosum moleculare in both CA1 and CA3 subfields. Furthermore, the intensity of immunostaining in lesion-only hippocampus seemed sparse in majority of GAD-67 interneurons, contrasting with the uniform intensity of immunostaining in GAD-67 interneurons of intact hippocampus.

\section{Location of transplants and selection of grafted animals for quantitative analysis of GAD-67 interneurons}

Analysis of Nissl-stained sections demonstrated discrete transplants in all the grafted animals. However, for quantification of GAD-67-positive interneurons in the host hippocampus, only those animals that exhibited the following criteria were selected: (1) a complete pyramidal cell loss in CA3b and CA3c and a partial cell loss in CA3a of hippocampus ipsilateral to the KA administration; (2) no apparent cell loss in CA1 and dentate granule cell layers of hippocampus ipsilateral to the KA administration; (3) intact CA3, CA1, and dentate granule cell layers in hippocampus contralateral to the KA administration; and (4) transplant location near the degenerated CA3 cell layer. Seventy-five percent of animals exhibited the above features and allowed selection of appropriate sections for GAD immunostaining and morphometric analysis. 

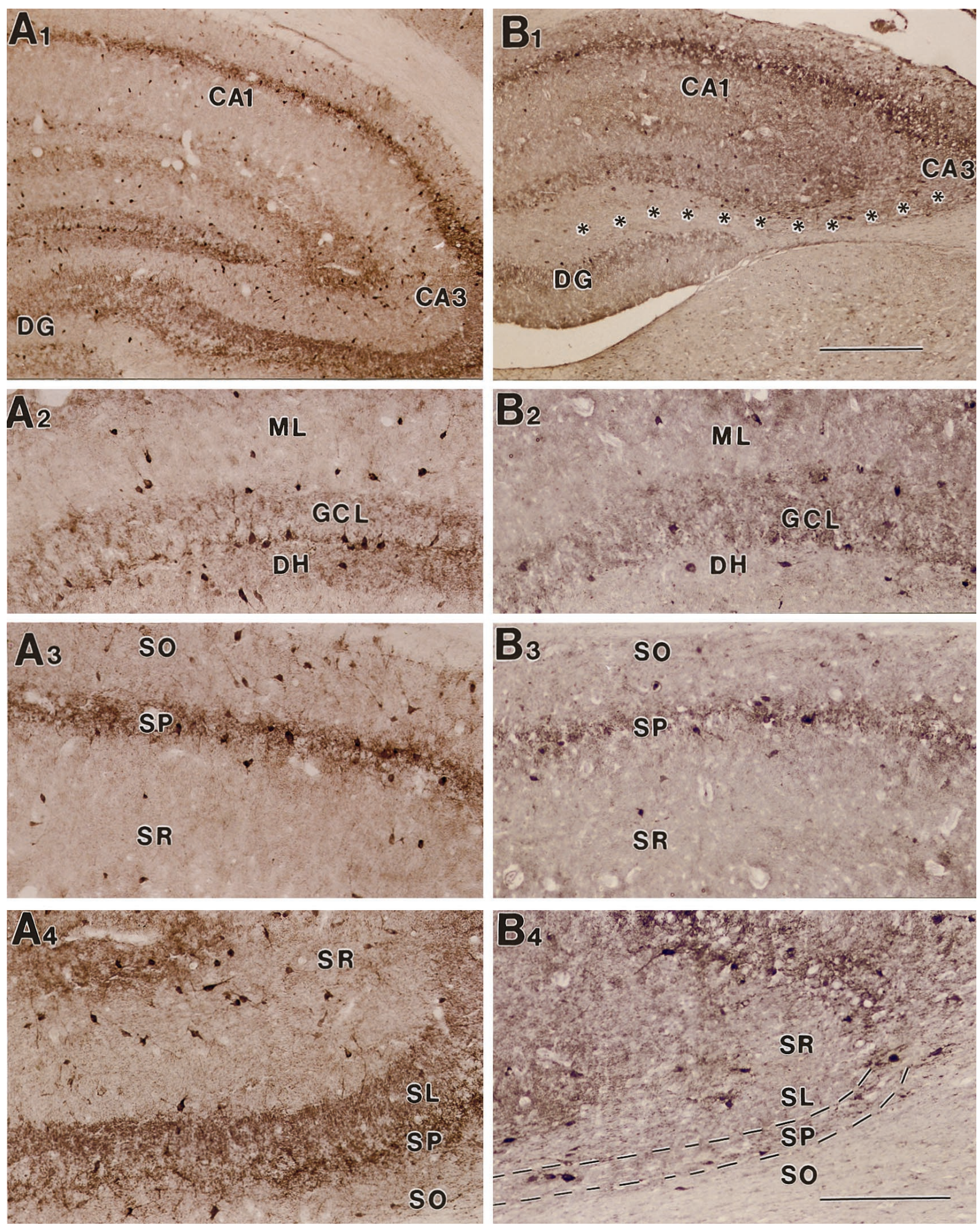

Figure 2. GAD-67-immunostained sections of the hippocampal formation from a control rat $\left(A_{1}\right)$ and a KA-treated rat $\left(B_{1}\right)$. $A_{2}-A_{4}$, Magnified views of dentate, CA1, and CA3 regions from $A_{1} ; B_{2}-B_{4}$, enlarged views of dentate, CA1, and CA3 regions from $B_{1}$. Note that the density of GAD-67-positive interneurons is clearly reduced in every layer of the KA-lesioned hippocampus $\left(B_{1}-B_{4}\right)$, compared with the intact control hippocampus $\left(A_{1}-A_{4}\right)$. Asterisks in $B_{1}$ denote the degenerated CA3 cell layer. $D G$, Dentate gyrus; $D H$, dentate hilus; $G C L$, granule cell layer; $M L$, molecular layer; $S L$, stratum lucidum; $S O$, stratum oriens; $S P$, stratum pyramidale; $S R$, stratum radiatum. Scale bars: $A_{1}, B_{1}, 400 \mu \mathrm{m} ; A_{2}-A_{4}, B_{2}-B_{4}, 200 \mu \mathrm{m}$.

\section{Cytoarchitecture of transplants}

Nissl staining demonstrated a large number of surviving neurons within all three types of grafts. Figure $3 A_{1}$ shows an example of mixed hippocampal cell graft located close to the degenerated CA3 cell layer. Neurons in all grafts were restricted to the immediate surrounding region of the injected site. Our earlier analysis of absolute cell survival within bromodeoxyuridine prelabeled grafts of mixed hippocampal, CA3, and CA1 cells have also indicated this phenomenon (Shetty and Turner, 1995b,c; Zaman et al., 2000). Mixed hippocampal transplants showed both larger pyramidalshaped neurons (presumably CA3 pyramidal neurons) and smaller neurons (presumably CA1 pyramidal cells and also some dentate 

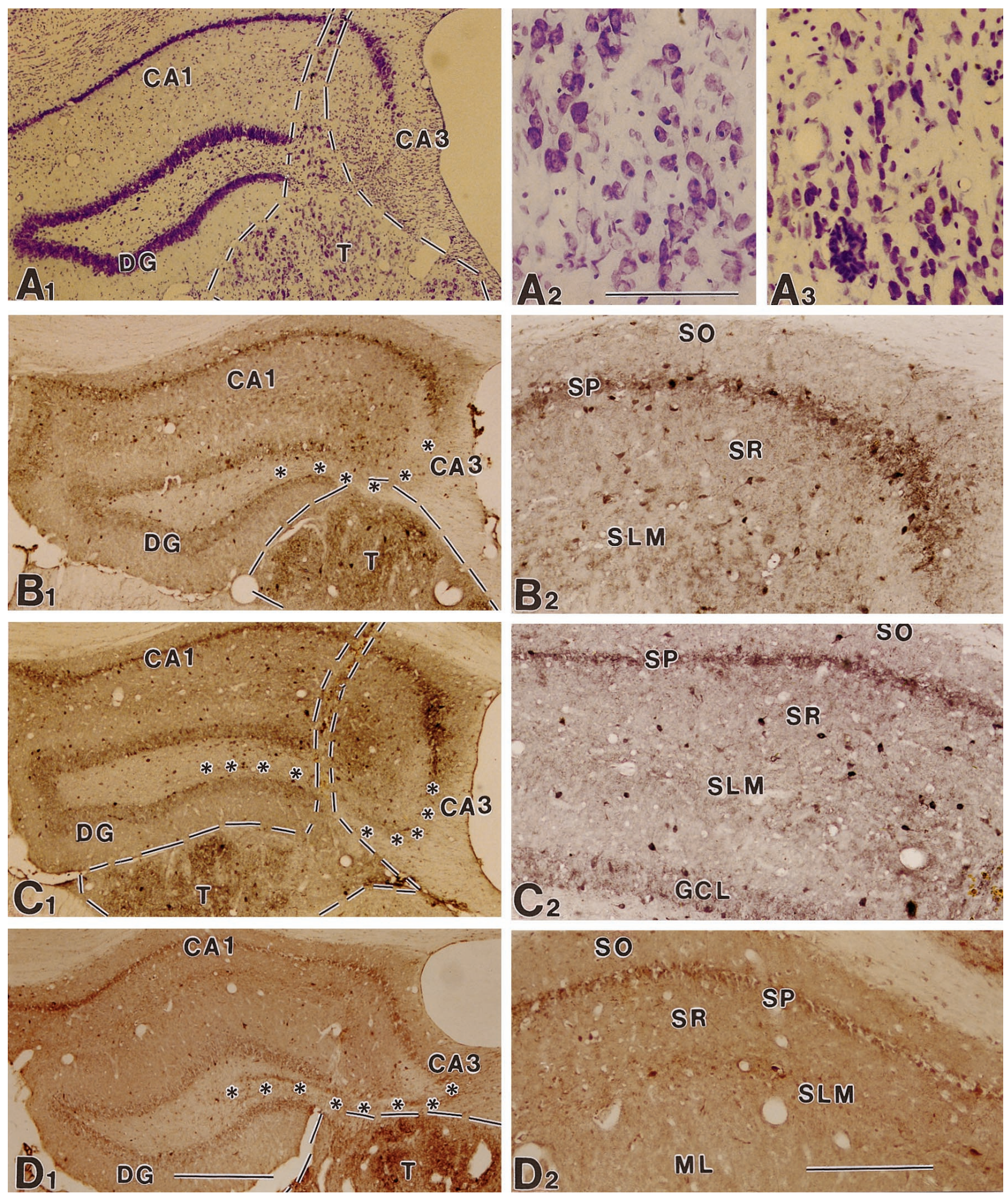

SO

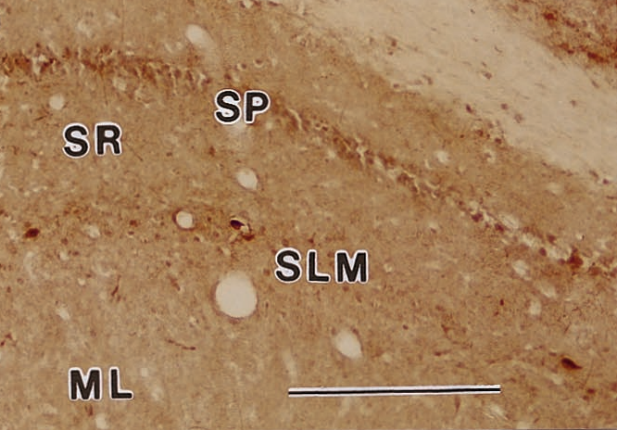

Figure 3. $A_{1}$, Nissl-stained section of the hippocampal formation from a KA-lesioned rat, which received mixed hippocampal cell transplant ( $T$ ) into the lesioned CA3 region at $45 \mathrm{~d}$ after KA administration. A large number of surviving neurons are seen in the graft area (outlined by interrupted lines in $A_{1}$ ). $A_{2}$, Magnified view of transplant region in $A_{1}$ showing clusters of larger CA3 pyramidal-like neurons. $A_{3}$ Mostly dispersed smaller neurons from a CA 1 cell graft. $B_{1}, C_{1}, D_{1}$, Examples of GAD-67-immunostained sections of the hippocampal formation from kainic acid-lesioned rats, which received fetal cell grafts at $45 \mathrm{~d}$ after lesion. $B_{1}$, Lesioned hippocampus that received mixed hippocampal cell transplant $(T)$; $C_{1}$, lesioned hippocampus that received CA 3 cell transplant $(T) ; D_{1}$, lesioned hippocampus that received CA1 cell transplant $(T)$. Note that the transplant (outlined by interrupted lines) is predominantly located just below the degenerated CA3 cell layer (asterisks) in all of these examples. $B_{2}, C_{2}, D_{2}$, Magnified views of CA1 regions from $B_{1}$, $C_{1}$, and $D_{1}$. Note that hippocampus receiving either mixed hippocampal or CA3 cell grafts $\left(B_{1}, B_{2}, C_{1}, C_{2}\right)$ exhibit greater density of GAD-67 interneurons than both lesion-only hippocampus (Fig. $\left.2 B_{1}-B_{4}\right)$ and hippocampus receiving CA1 cell graft $\left(D_{1}, D_{2}\right)$. GAD-67 interneuron density in $B_{1}$ and $C_{1}$ are also comparable with the control hippocampus (Fig. $2 A_{1}$ ). $D G$, Dentate gyrus; $G C L$, granule cell layer; $M L$, molecular layer; $S L M$, stratum lacunosum moleculare; $S O$, stratum oriens; $S P$, stratum pyramidale; $S R$, stratum radiatum. Scale bars: $A_{1}, B_{1}, C_{1}, D_{1}, 400 \mu \mathrm{m} ; A_{2}, A_{3}, 100 \mu \mathrm{m} ; B_{2}, C_{2}, D_{2},=200 \mu \mathrm{m}$. 
granule cells). Larger CA3 pyramidal neurons within both mixed hippocampal and specific CA3 cell grafts were organized in clusters (Fig. $3 A_{2}$ ). In contrast, neurons within CA1 transplants were mostly dispersed and much smaller than those in either mixed hippocampal or CA3 transplants (Fig. $3 A_{3}$ ). The types of neurons encountered within these three types of transplants have been characterized quantitatively and described in our earlier reports (Shetty and Turner, 1995b,c; Zaman et al., 2000). These results have mainly shown the following: (1) mixed hippocampal transplants contain both CA3 and CA1 pyramidal neurons; (2) the size of neurons encountered within CA3 and CA1 transplants are respectively comparable with hippocampal CA3 and CA1 neurons developed in situ; and (3) a large number of neurons within both mixed hippocampal and CA3 cell grafts express CA3 pyramidal cell-specific markers, such as nonphosphorylated neurofilament proteins, but neurons within CA1 cell grafts do not express these proteins. Thus, both mixed hippocampal and CA3 transplants contain a large number of CA3 pyramidal neurons, whereas CA1 transplants contain mostly CA1 pyramidal neurons.

\section{GAD-67-positive interneurons in CA3-lesioned and grafted hippocampus}

Interneurons positive for GAD-67 were present in all strata within different subfields of all lesioned and grafted hippocampus (Fig. $\left.3 B_{1}, C_{1}, D_{1}\right)$. However, hippocampus containing either mixed hippocampal or CA3 cell grafts appeared to have an interneuron density nearly that of the intact hippocampus and significantly greater than lesion-only hippocampus (Figs. 2-5). In dentate gyrus, recovery of GAD-67 interneurons was conspicuous in the dentate hilus (particularly basket cells at the junction of the hilus and the granule cell layer; Fig. $4 A_{3}, A_{4}$ ), whereas in CA1 and CA3 subfields, recovery of GAD-67 interneurons appeared prominent in stratum radiatum (Figs. $4 B_{3}, B_{4}, 5 A_{3}, A_{4}$ ). In hippocampus containing CA1 cell grafts, GAD-67 interneuron density appeared similar to lesion only animals (Figs. $3 D_{1}, D_{2}, 4 A_{5}, B_{5}, 5 A_{5}$ ). The latter two groups also differed from the other three groups (intact hippocampus and lesioned hippocampus with either mixed hippocampal or CA3 cell grafts) by sparse immunoreaction in most of GAD 67-positive interneurons throughout the hippocampus (Figs. 2-5). Analysis of grafts in GAD-67-immunostained sections revealed prominent interneurons within all grafts, regardless of the cell type grafted (Fig. $\left.3 B_{1}, C_{1}, D_{1}\right)$. The area within grafts also exhibited a much higher density of GAD-67 terminals than host regions.

\section{GAD-67-positive interneuron counts}

We quantified GAD-67 positive hippocampal interneurons as the density per cubic millimeter volume of layer, the density per millimeter of pyramidal cell layer, and the density per section (Shetty and Turner, 1999c). We found that the results were consistent with all of the above three methods (data not shown). These results included the extent of reduction in GAD-67 interneuron density within lesion-only hippocampus and the lesioned hippocampus receiving CA1 cell grafts compared with the intact control hippocampus and the overall degree of recovery in the lesioned hippocampus receiving grafts containing CA3 cells. However, among these three counting methods, we chose measurement of density per cubic millimeter volume of tissue to present in this study, because this method involved appropriate correction for both the soma size of interneurons in different groups and also the tissue shrinkage in the KAlesioned hippocampus and the KA-lesioned hippocampus receiving various grafts. This method is also consistent with previous studies on GAD-67-positive interneuron counts in the lesioned hippocampus (Mathern et al., 1995; Morin et al., 1998).

The numerical density of GAD-67-positive interneurons was quantified in the dentate gyrus and CA1 and CA3 subfields. Values in these regions were expressed both as the density per cubic millimeter volume of the entire region and as the density per cubic millimeter volume of the individual layer. Cumulative interneuron counts from different regions of the septal hippocampus were also expressed as the density per cubic millimeter volume of the entire septal hippocampus. Values were compared between the intact control group $(n=8)$ and each of the four lesioned groups $(n=6$ per group) using ANOVA with the Student-Newman-Keuls multiple comparison post hoc test. This comparison revealed the following: (1) a dramatic reduction in GAD-67 interneuron density within all subfields of the lesion only hippocampus; (2) significant improvement of GAD-67 interneuron density within all regions of the lesioned hippocampus with grafting of either mixed hippocampal or CA3 cells; and (3) no improvement of GAD-67 interneuron density within all subfields of the lesioned hippocampus with grafting of CA1 cells. These density measurements involved appropriate correction for both cell size and tissue shrinkage attributable to the degeneration of CA3 pyramidal cells and transplantation. Therefore, the substantial differences in GAD-67 interneuron density observed between different groups strongly point to an explicit reduction in the density of GAD-67 interneurons with KA-induced degeneration of the CA3 pyramidal cells in lesion-only hippocampus, and to a restoration of GAD-67 interneuron density with grafting of either mixed hippocampal or CA3 cell grafts. Recovery in the density of GAD-67 interneurons in the lesioned hippocampus after grafting of appropriate cells further indicates that reductions in GAD-67 interneuron density are a result of the loss of GAD-67 expression in a major fraction of interneurons after KAinduced CA3 cell loss, rather than interneuron cell death. The similar density of Nissl-stained interneurons between intact and lesioned hippocampus observed in our recent study also corroborates this conclusion (Shetty and Turner, 2000; our unpublished observations). Quantitative data pertaining to these findings are detailed below for each hippocampal subfield.

\section{Density of GAD-67 interneurons in the dentate gyrus}

Comparison of GAD-67 interneuron density in the dentate gyrus between different groups using ANOVA with the Student-NewmanKeuls multiple comparisons test revealed significant differences between different groups ( $p<0.001)$. Density of GAD-67 interneurons in the dentate gyrus of lesion only hippocampus was significantly reduced compared with the dentate gyrus of the intact control hippocampus (Fig. $6 ; p<0.001$ ). The overall density for the entire dentate gyrus was only $39 \%$ of the intact control value. Among different layers of the dentate gyrus, reduction was maximal in the dentate granule cell layer (21\% of control; $p<0.001)$ and moderate in the dentate hilus and the molecular layer $(40-$ $61 \%$ of control; $p<0.05)$.

In the lesioned hippocampus receiving grafts of either mixed hippocampal cells or CA3 cells, the density of GAD-67 interneurons in the entire dentate gyrus was fully restored to that in the intact control hippocampus (Fig. 6; $107 \%$ of control with mixed hippocampal cell grafting and $102 \%$ of control with CA3 cell grafting). This density was $>230 \%$ of that observed in lesion-only hippocampus $(p<0.01)$. Among individual layers of the dentate gyrus, the dentate hilus and the molecular layer showed a similar trend in recovery of GAD-67 interneuron density after transplantation of either mixed hippocampal or CA3 cell grafts (Fig. 6). However, in the granule cell layer, GAD-67 interneuron density was significantly less than in the control intact hippocampus (58$63 \%$ of control; $p<0.05$ ) but $272-296 \%$ of lesion-only hippocampus $(p<0.05)$. In the lesioned hippocampus receiving grafts of CA1 cells, the GAD-67 interneuron density for both the entire as well as different layers of the dentate gyrus was significantly less than in the intact control hippocampus $(p<0.01)$ and highly comparable with lesion-only hippocampus ( $p>0.05$; Fig. 6). Thus, transplantation of either mixed hippocampal or CA3 cells into the lesioned CA 3 region at $45 \mathrm{~d}$ after lesion restores the overall density of GAD-67 interneurons in the dentate gyrus of the lesioned hippocampus to that found in the dentate gyrus of the intact control hippocampus by 6 months after lesion. Of its different layers, recovery is complete in the dentate hilus and the molecular layer but only partial in the granule cell layer. The effect is highly similar with transplantation of either mixed hippocampal cells or CA3 cells. On the other hand, transplantation of fetal CA1 cells 

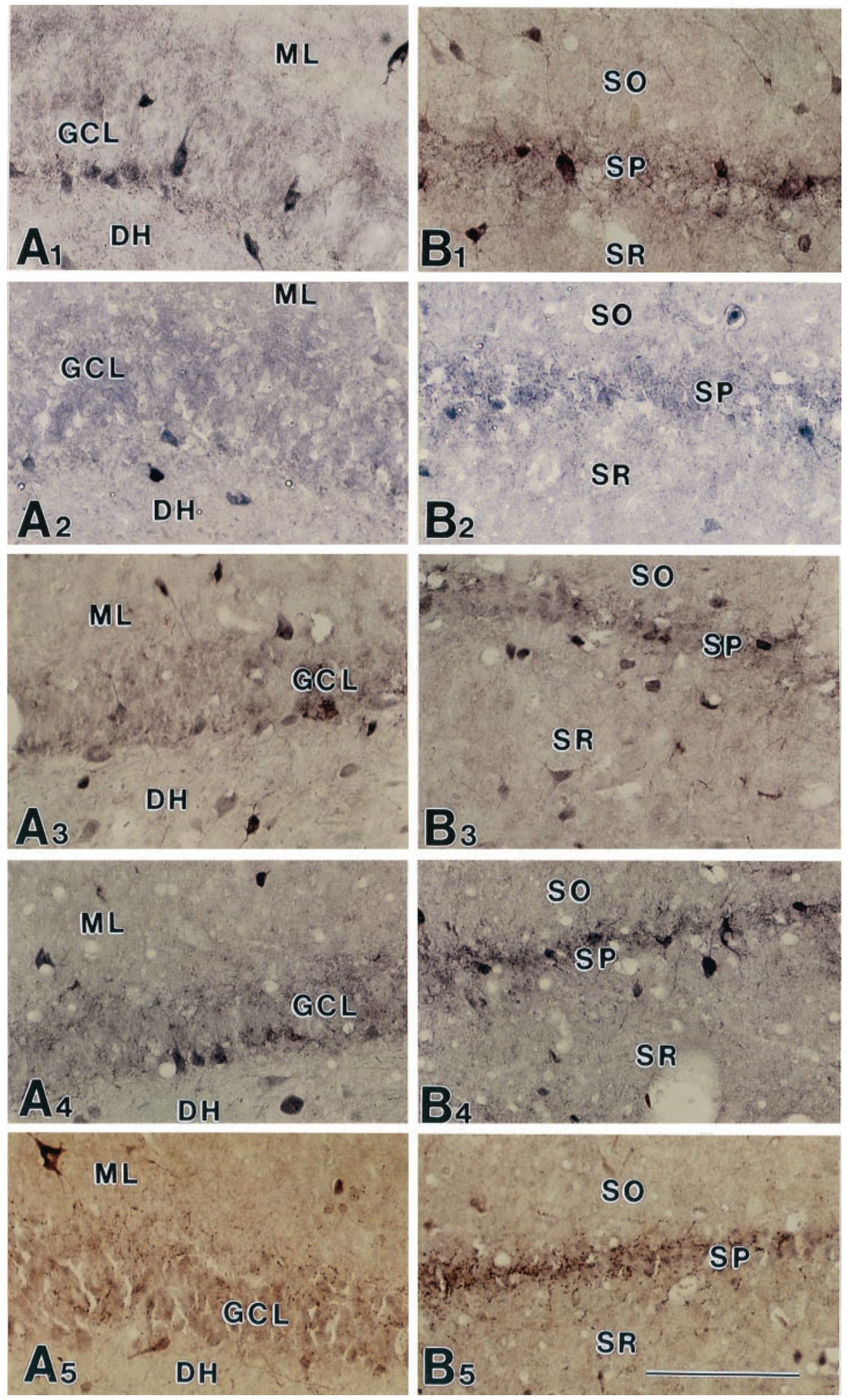

Figure 4. Comparison of the distribution of GAD-67-positive interneurons in the dentate gyrus $\left(A_{1}-A_{5}\right)$ and the CA1 subfield $\left(B_{1}-B_{5}\right)$ of the intact control hippocampus $\left(A_{1}, B_{1}\right)$, the KAlesioned hippocampus $\left(A_{2}, B_{2}\right)$, the KA-lesioned hippocampus receiving mixed hippocampal cell graft $\left(A_{3}, B_{3}\right)$, the KA-lesioned hippocampus receiving CA3 cell graft $\left(A_{4}, B_{4}\right)$, and the KAlesioned hippocampus receiving CA1 cell graft $\left(A_{5}, B_{5}\right)$. Note that compared with the intact hippocampus $\left(A_{1}, B_{1}\right)$, GAD-67-positive interneuron density appears decreased in both dentate gyrus and CA1 subfield of lesion-only hippocampus $\left(A_{2}, B_{1}\right)$ and the hippocampus receiving CA1 cell graft $\left(A_{5}, B_{5}\right)$. In contrast, both of these regions in the lesioned hippocampus receiving either mixed hippocampal or CA3 cell grafts $\left(A_{3}, A_{4}, B_{3}, B_{4}\right)$ exhibit interneuron density that is closer to the intact hippocampus. In dentate gyrus, recovery is apparent in the dentate hilus, including basket cells at the junction of hilus and granule cell layer, whereas in the CA1 subfield, recovery is conspicuous in strata radiatum and pyramidale. $D H$, Dentate hilus; $G C L$, granule cell layer; $M L$, molecular layer; $S O$, stratum oriens; $S P$, stratum pyramidale; $S R$, stratum radiatum. Scale bar, $100 \mu \mathrm{m}$. does not improve the density of GAD-67 interneurons in any of the layers of the dentate gyrus.

\section{Density of GAD-67-positive interneurons in the CA1 subfield}

Statistical comparison of GAD-67 interneuron density in the CA1 subfield revealed significant differences between different groups $(p<0.0001)$. Like the dentate gyrus, the density of GAD-67 interneurons in the CA1 subfield of lesion only hippocampus was dramatically reduced compared with the intact control hippocam- pus (Fig. 7; $p<0.001$ ). Density of GAD-67 interneurons for the entire CA1 subfield was only $24 \%$ of that in the intact control hippocampus. Among different strata of the CA1 subfield, reduction was maximal in the stratum pyramidale ( $28 \%$ of control; $p<$ $0.01)$ and less pronounced in strata oriens and radiatum $(39-44 \%$ of control; $p<0.05)$.

Density of GAD-67 interneurons within the entire CA1 subfield of the lesioned hippocampus receiving grafts of either mixed hippocampal cells or CA3 cells was fully restored to that observed in the intact control hippocampus (Fig. $7 ; p>0.05$ ). Density recov- 

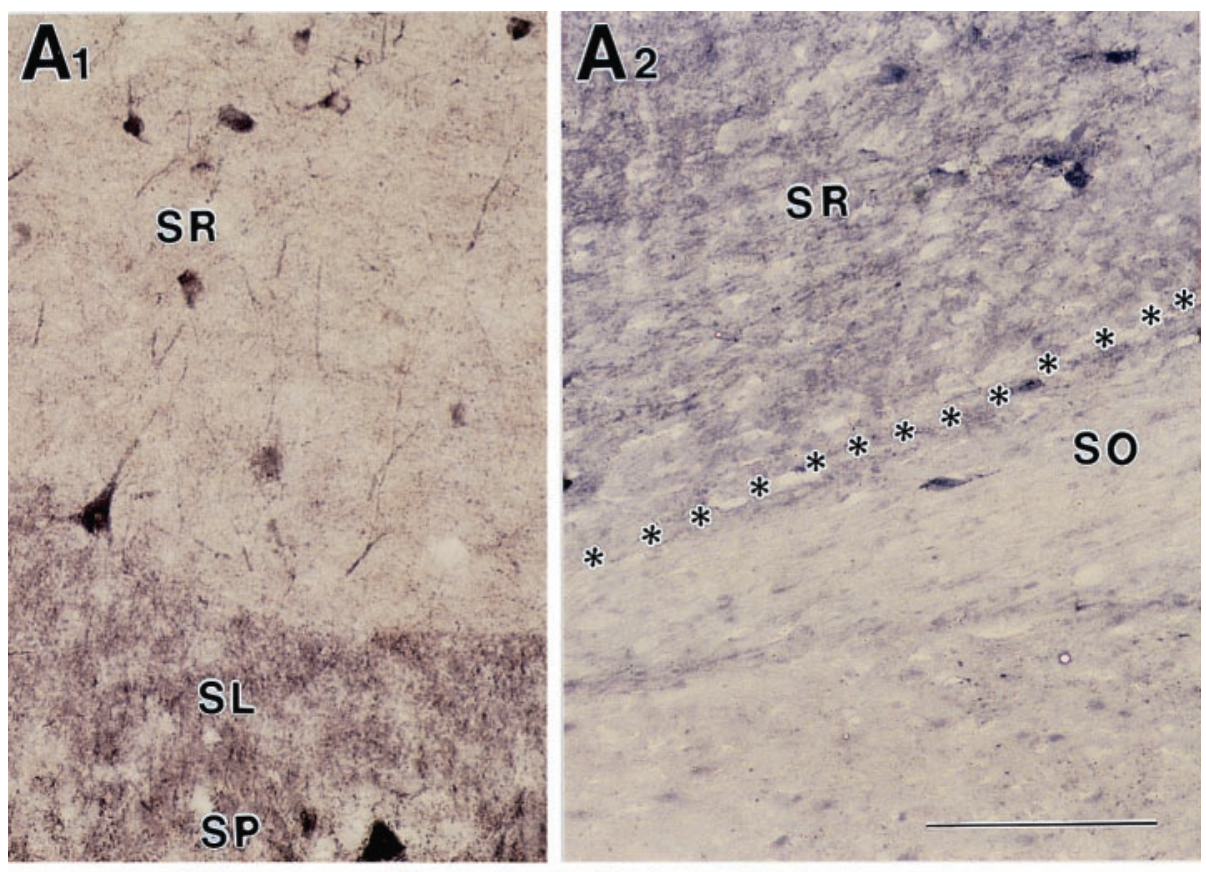

Figure 5. Comparison of the distribution of GAD-67-positive interneurons in the CA3 subfield $\left(A_{1}-A_{5}\right)$ of the control hippocampus $\left(A_{1}\right)$, the KA-lesioned hippocampus $\left(A_{2}\right)$, the KA-lesioned hippocampus receiving mixed hippocampal cell graft $\left(A_{1}\right)$, the KA-lesioned hippocampus receiving $\mathrm{CA} 3$ cell graft $\left(A_{4}\right)$, and the KA-lesioned hippocampus receiving CA1 cell graft $\left(A_{5}\right)$. Compared with the intact hippocampus $\left(A_{I}\right)$ a clear decrease in GAD-67-positive interneuron density is obvious in the CA3 subfield of both lesion-only hippocampus $\left(A_{2}\right)$ and the lesioned hippocampus receiving CA1 cell graft $\left(A_{5}\right)$. In contrast, the CA3 region (particularly stratum radiatum) in hippocampus receiving either mixed hippocampal or CA3 cell grafts $\left(A_{3}, A_{4}\right)$ exhibits interneuron density that is closer to intact hippocampus. The interrupted line in $A_{5}$ denotes transplant-host interface; asterisks denote the degenerated CA3 cell layer. $S L$, Stratum lucidum; $S O$, stratum oriens; $S P$, stratum pyramidale; $S R$, stratum radiatum. Scale bar, $100 \mu \mathrm{m}$.
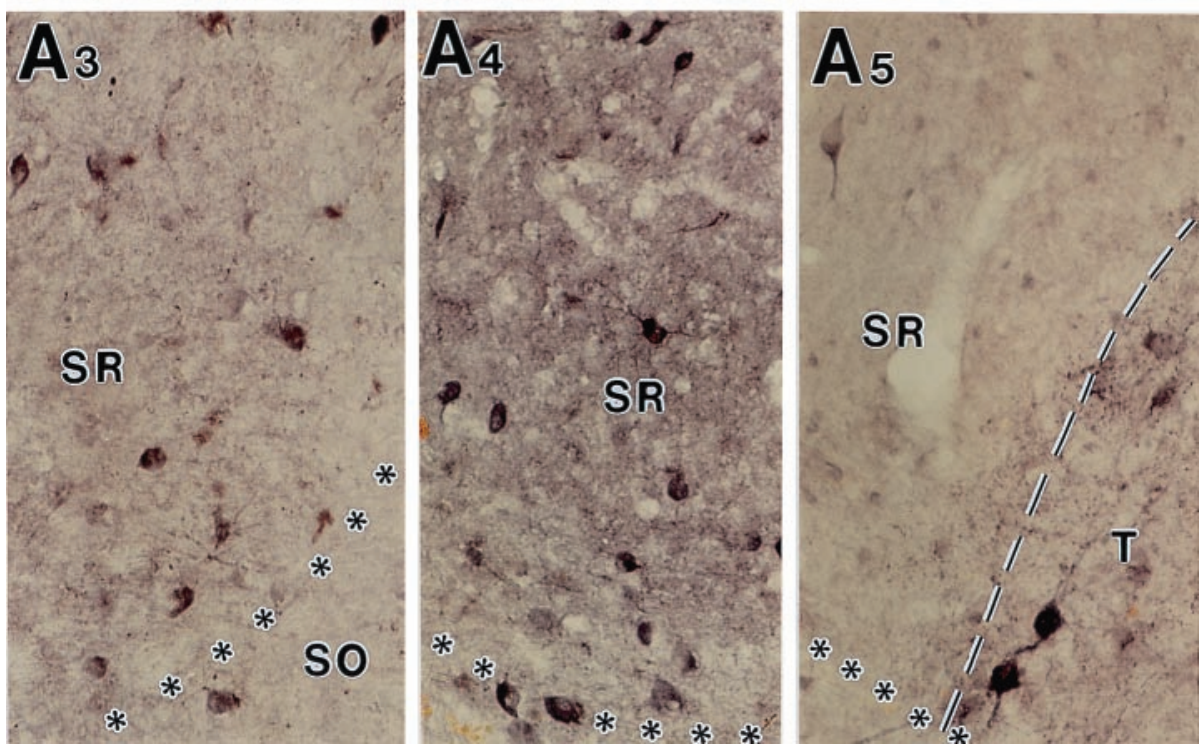

ered to $94 \%$ of the control with mixed hippocampal cell grafting and $117 \%$ of the control with CA3 cell grafting. However, statistically, the recovery mediated by mixed hippocampal and CA3 cell grafts was similar. Compared with lesion-only hippocampus, the density of GAD-67 interneurons in these groups was significantly enhanced (383-477\%; $p<0.05$; Fig. 7). Among different layers of the CA1 subfield, strata oriens and radiatum showed complete recovery of GAD-67 interneuron density with transplantation of either mixed hippocampal or CA3 cell grafts (81-116\% of control hippocampus and $184-297 \%$ of lesion-only hippocampus). However, the density of GAD-67 interneurons in the stratum pyramidale showed complete recovery with only CA3 cell grafts ( $99 \%$ of control and $357 \%$ of lesion-only hippocampus). With mixed hippocampal cell grafting, density in this layer, although statistically reached closer to the control value $(p>0.05)$, did not show significant improvement over lesion-only hippocampus $(p>0.05)$. In the lesioned hippocampus having grafts of CA1 cells, interneuron density within the entire region as well as different strata of the CA1 subfield remained significantly less than the control values $(p<0.05)$ and highly comparable with lesion-only hippocampus $(p>0.05)$. Thus, grafting of either mixed hippocampal or CA3 cell transplants into the lesioned $\mathrm{CA} 3$ region at $45 \mathrm{~d}$ after lesion restores the overall density of interneurons in the CA1 subfield of the lesioned hippocampus to control levels by 6 months after lesion. Among individual strata of the CA1 subfield, all strata show complete recovery with CA3 cell grafting. In contrast, with mixed hippocampal cell grafting, the recovery is complete in strata oriens and radiatum but only partial in the stratum pyramidale. Transplantation of fetal CA1 cells, on the other hand, has no positive effect on any strata of the CA1 subfield.

\section{Density of GAD-67 interneurons in the CA3 subfield}

Density of GAD-67 interneurons in the CA3 subfield revealed highly significant differences between different groups $(p<$ 0.0001 ). In lesion only hippocampus, density was reduced dramatically compared with the intact control hippocampus (Fig. $8 ; p<$ 0.001). Density of GAD-67 interneurons for the entire CA3 subfield was only $30 \%$ of that in the intact control hippocampus. Reductions were also very significant in all strata of the CA3 subfield (stratum oriens, $24 \%$ of control; $p<0.001$; strata radiatum and pyramidale, $32-35 \%$ of control; $p<0.01$ ).

Unlike the dentate gyrus and the CA1 subfield, transplantation of mixed hippocampal or CA3 cell grafts led to only partial recovery in the density of GAD-67 interneurons in the CA3 subfield. 


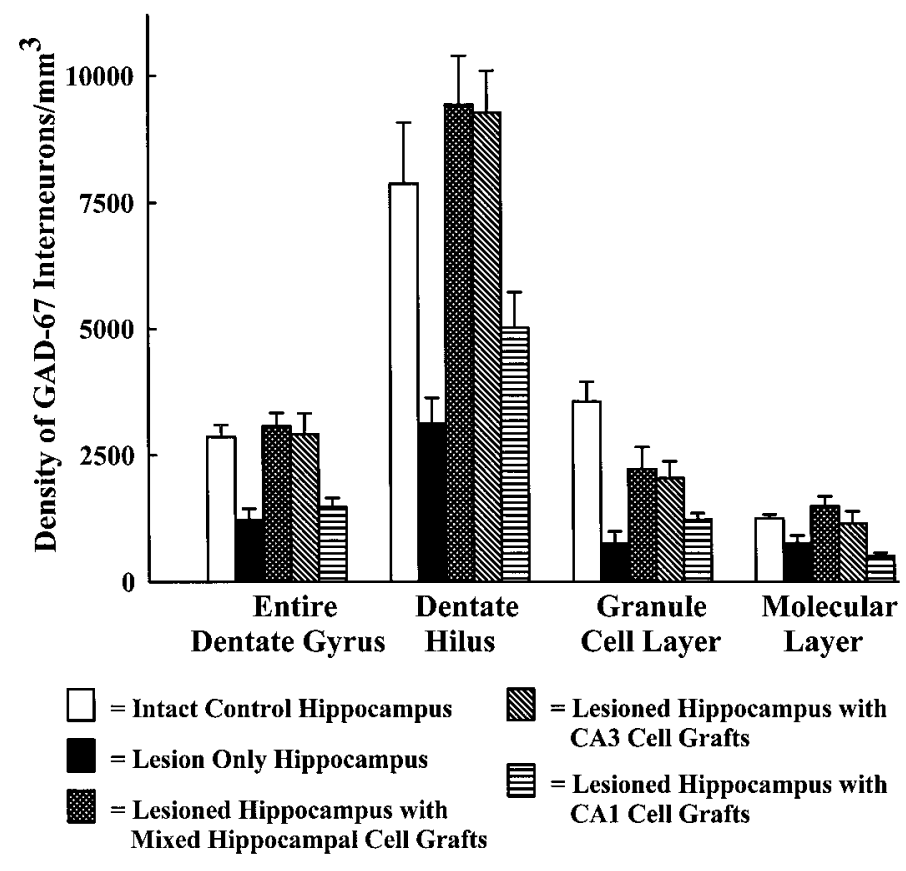

Figure 6. Histogram comparing GAD-67-positive interneuron density per cubic millimeter volume of tissue in both the entire and different layers of the dentate gyrus among the control intact hippocampus $(n=8)$, the lesioned hippocampus at 6 months after lesion, the lesioned hippocampus receiving mixed hippocampal cell graft, the lesioned hippocampus receiving CA3 cell graft, and the lesioned hippocampus receiving CA1 cell graft $(n=6$ in each group). ANOVA with the Student-Newman-Keuls multiple comparisons post hoc test reveals significant differences between groups $(p<0.0001)$. Compared with the intact control hippocampus, interneuron density in lesion-only hippocampus and the lesioned hippocampus receiving CA1 cell graft is significantly reduced for the entire dentate gyrus $(p<$ $0.001)$ as well as for all three layers of the dentate gyrus $(p<0.05)$. In contrast, interneuron density in dentate gyrus of lesioned hippocampus receiving grafts of either mixed hippocampal or CA3 cells is comparable with that in the intact control hippocampus $(p>0.05)$ and significantly greater than both lesion-only hippocampus and lesioned hippocampus receiving CA1 cell grafts $(p<0.05)$. The only exception is the granule cell layer, where the recovery is partial (i.e., significantly greater than lesiononly hippocampus but significantly less than control hippocampus; $p<$ $0.05)$. Values are means \pm SE.

GAD-67 interneuron density in the entire CA3 subfield of the lesioned hippocampus receiving grafts of either mixed hippocampal or CA3 cells remained significantly less than the intact control hippocampus $(66-68 \%$ of control; $p<0.05$; Fig. 8) but improved significantly compared with lesion-only hippocampus (222-229\% of lesion-only hippocampus; $p<0.05$ ). The extent of enhancement in GAD-67 interneuron density was highly comparable between mixed hippocampal and CA3 cell grafts, suggesting that both mixed hippocampal and CA3 cell grafts have equivalent effects on the recovery of GAD-67 interneuron density in the CA3 subfield of the lesioned hippocampus. Of different layers of the CA3 subfield, the stratum radiatum exhibited complete recovery in GAD-67 interneuron density with grafting of either mixed hippocampal or CA3 cells; density was $84-109 \%$ of the control hippocampus $(p>$ $0.05)$ and $259-337 \%$ of lesion-only hippocampus $(p<0.01)$. Strata oriens and pyramidale showed no significant recovery in GAD-67 interneuron density with transplantation of either mixed hippocampal or CA3 cell grafts and remained comparable with lesion-only hippocampus (Fig. 8). Interneuron density within the entire as well as different strata of the CA3 subfield of the lesioned hippocampus receiving grafts of CA1 cells was significantly less than the control hippocampus $(p<0.05)$ and highly comparable with lesion-only hippocampus $(p>0.05)$. Thus, grafting of either mixed hippocampal or CA3 cell transplants into the lesioned CA3 region at $45 \mathrm{~d}$ after lesion partially restored the overall density of host GAD-67 interneurons in the CA3 region by 6 months after lesion. Among its strata, only the stratum radiatum exhibited complete recovery,
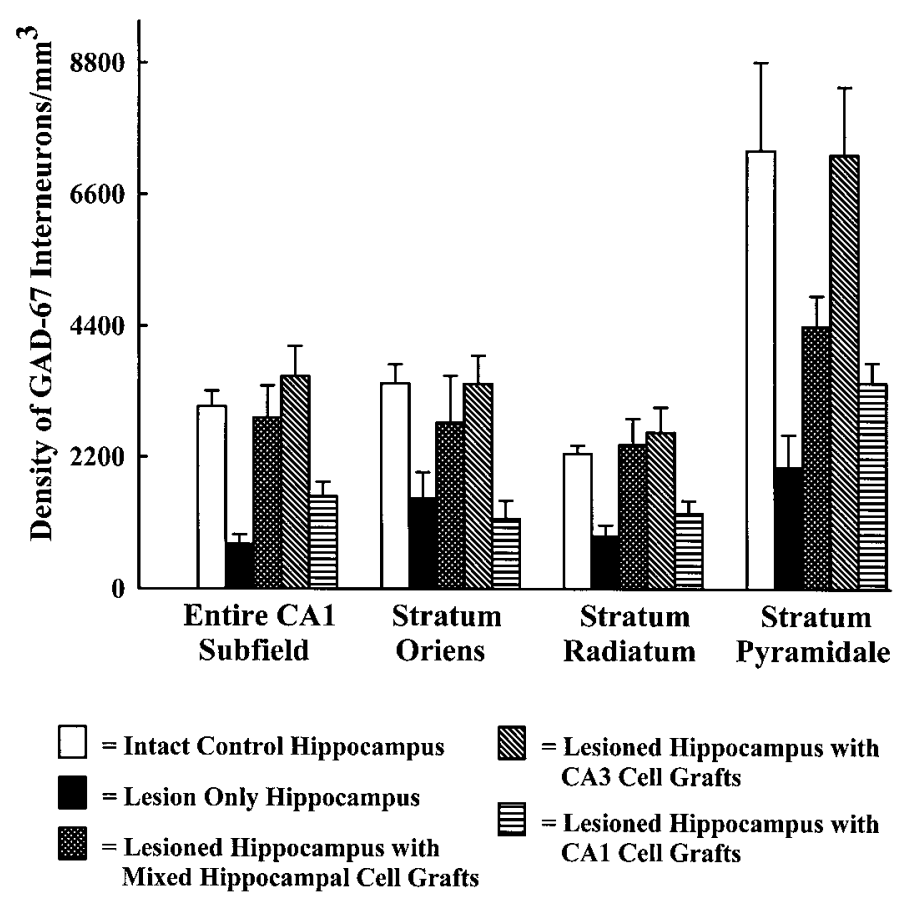

Figure 7. Histogram comparing the density of GAD-67 interneurons per cubic millimeter volume of tissue in both the entire and different strata of the CA1 subfield among the intact control hippocampus $(n=8)$, the lesioned hippocampus at 6 months after lesion, the lesioned hippocampus receiving mixed hippocampal cell graft, the lesioned hippocampus receiving CA 3 cell graft, and the lesioned hippocampus receiving CA1 cell graft ( $n=6$ in each group). ANOVA reveals significant differences between groups $(p<0.0001)$. Note that compared with the intact control hippocampus, interneuron density in lesion-only hippocampus and the hippocampus receiving CA1 cell graft is significantly reduced for the entire CA1 subfield $(p<0.001)$ and also for all layers of the CA1 subfield $(p<0.05)$. However the interneuron density in the CA1 subfield of the lesioned hippocampus receiving grafts of either mixed hippocampal or CA3 cells is comparable with that in the control intact hippocampus $(p>0.05)$ and significantly greater than both lesion-only hippocampus and hippocampus receiving CA1 cell graft $(p<0.05)$. The only exception is the stratum pyramidale of the lesioned hippocampus receiving mixed hippocampal transplants, where recovery of GAD-67 interneuron density is partial (i.e., significantly comparable with control intact hippocampus but not significantly greater than lesion-only hippocampus; $p>0.05)$. Values are means $\pm \mathrm{SE}$.

whereas, in strata oriens and pyramidale, there was no significant recovery with either mixed hippocampal or CA3 cell transplantation. In contrast, transplantation of fetal CA1 cells had no positive effect on any strata of the CA3 subfield, consistent with the effects of CA1 cell grafts on GAD-67 interneuron density observed in the dentate gyrus and the CA1 subfield.

\section{Mean density of GAD-67 interneurons in the entire septal hippocampus}

Density of GAD 67-interneurons per cubic millimeter volume of the entire septal hippocampus showed significant differences between different groups ( $p<0.0001$; Fig. 9). The overall GAD-67 interneuron density was only $37 \%$ of the control value in lesiononly hippocampus $(p<0.01)$. With mixed hippocampal cell grafting into the lesioned CA3 region, it improved to $86 \%$ of the intact control hippocampus, and with CA3 cell grafting it improved to $89 \%$ of the intact control hippocampus ( $p>0.05$; Fig. 9). In contrast, with CA1 cell grafting, the density of GAD-67 interneurons remained dramatically less than the control hippocampus (44\% of control; $p<0.001$; Fig. 9) and closer to that of lesion-only hippocampus ( $p>0.05$; Fig. 9). The overall density in the lesioned hippocampus having either mixed hippocampal or CA3 cell grafts was $236-242 \%$ of lesion-only hippocampus $(p<0.01)$ and $195-$ $200 \%$ of the hippocampus receiving CA1 cell grafts $(p<0.01)$. Thus, the CA3-lesioned hippocampus, as a whole, clearly exhibited normalization in the overall density of GAD-67 interneurons with 

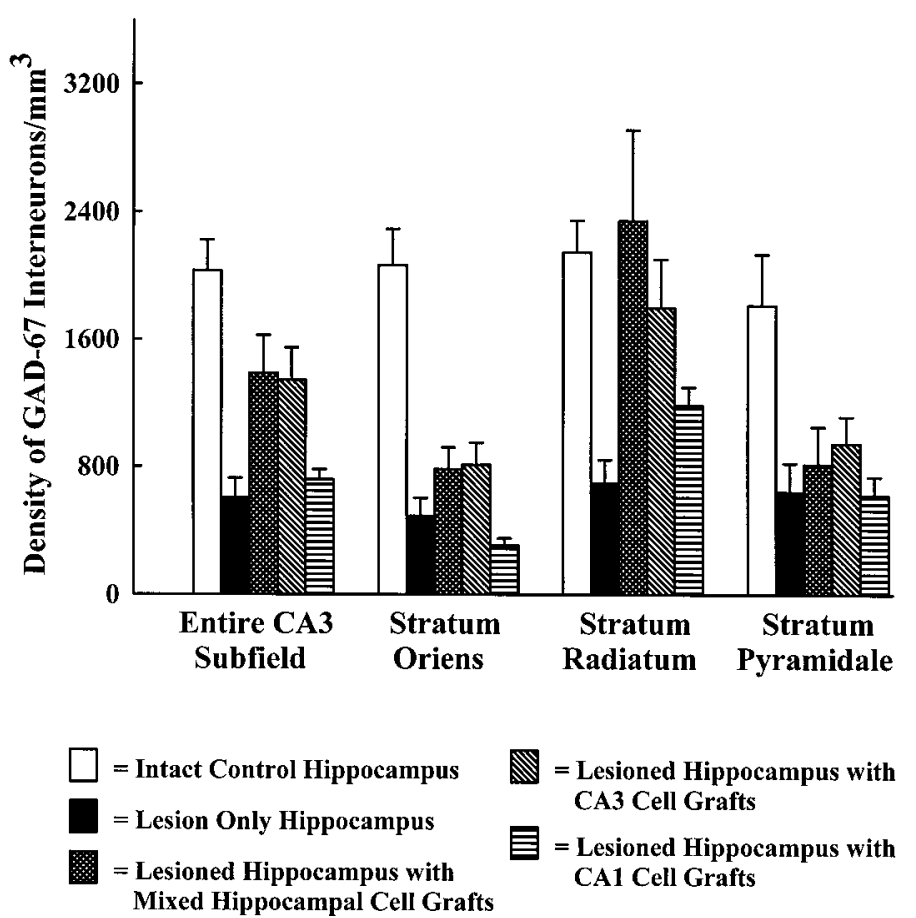

= Lesioned Hippocampus with CA3 Cell Grafts

$=$ Lesioned Hippocampus with CA1 Cell Grafts
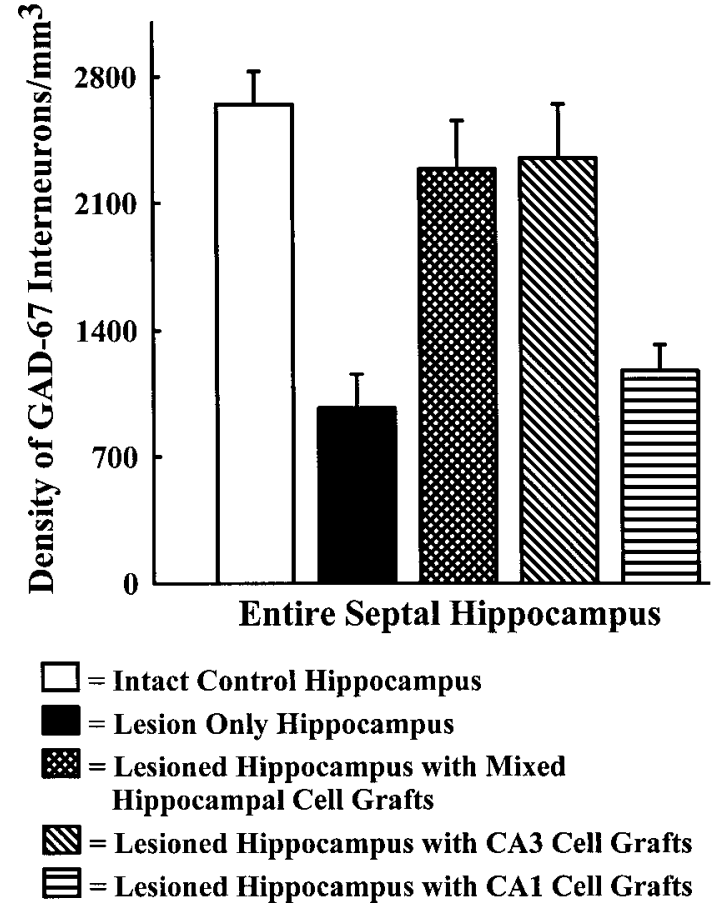

Figure 8. Histogram showing GAD-67 interneuron density per cubic millimeter volume of tissue in both the entire and different strata of the CA3 subfield. Comparison among the control intact hippocampus $(n=8)$, the lesioned hippocampus at 6 months after lesion, the lesioned hippocampus receiving mixed hippocampal cell graft, the lesioned hippocampus receiving CA3 cell graft, and the lesioned hippocampus receiving CA1 cell graft ( $n=6$ in each group) using ANOVA reveals significant differences $(p<$ $0.0001)$. The GAD interneuron density in lesion-only hippocampus and the hippocampus receiving CA1 cell graft is significantly reduced for the entire CA3 subfield $(p<0.001)$ and for all different strata of the CA3 subfield $(p<0.05)$ compared with the control intact hippocampus. Interneuron density in the entire CA3 region of the lesioned hippocampus receiving grafts of either mixed hippocampal or CA3 cells is significantly less than that of the intact hippocampus $(p<0.05)$ but significantly greater than both lesion-only hippocampus and hippocampus receiving CA1 cell graft $(p<$ $0.05)$, suggesting partial recovery of GAD-67 interneuron density with mixed hippocampal or CA3 cell grafting. Among different layers, only stratum radiatum exhibited complete recovery with mixed hippocampal or CA3 cell grafting; density was comparable with intact control hippocampus $(p>0.05)$ and significantly greater than lesion-only hippocampus $(p<$ $0.01)$. GAD-67 interneuron density in strata oriens and pyramidale remained less than intact control hippocampus $(p<0.05)$ and comparable with lesion-only hippocampus and hippocampus receiving CA1 cell grafts $(p>0.05)$. Values are means $\pm \mathrm{SE}$.

transplantation of either mixed hippocampal or CA3 cells but showed no improvement with transplantation of only CA1 cells.

\section{Size of interneurons in different subfields of intact, lesion-only, and lesioned and grafted hippocampi}

Compared with the intact hippocampus, there was significant hypertrophy of GAD-67-positive interneurons in the dentate gyrus and the CA3 subfield of lesion only hippocampus $(p<0.05$; Fig. $10)$. The mean diameter was increased by $21 \%$ in the dentate gyrus and $17 \%$ in the CA3 subfield. However, the mean diameter of GAD-67 interneurons in the lesioned hippocampus with fetal grafts (mixed hippocampal, CA3, or CA1 cell grafts) was comparable with those in the intact hippocampus (Fig. 10). Thus, there clearly occurs a significant enlargement in the size of GAD-67 interneurons within both dentate gyrus and CA3 subfield of lesiononly hippocampus but not in the lesioned hippocampus receiving fetal cell grafts. These results suggest that a decrease in the number of GAD-67 interneurons within lesion-only hippocampus is not attributable to shrinkage in the size of interneurons with the CA3 lesion. Furthermore, it is clear that a higher density of interneurons in the lesioned hippocampus having grafts of either mixed hippocampal or CA3 cells than lesion-only hippocampus is not attrib-

Figure 9. Histogram comparing GAD-67 interneuron density per cubic millimeter volume of tissue in the entire septal hippocampus among the control intact hippocampus $(n=8)$, the lesioned hippocampus at 6 months after lesion, the lesioned hippocampus receiving mixed hippocampal cell graft, the lesioned hippocampus receiving CA3 cell graft, and the lesioned hippocampus receiving CA1 cell graft ( $n=6$ in each group). ANOVA analysis with the Student-Newman-Keuls multiple comparisons post hoc test reveals significant differences among groups $(p<0.0001)$. Note that the density of GAD interneurons in lesion-only hippocampus and hippocampus receiving CA1 cell grafts is significantly reduced compared with control intact hippocampus $(p<0.01)$. In contrast, GAD interneuron density in lesioned hippocampus receiving grafts of either mixed hippocampal or CA3 cells shows complete recovery. Density is highly comparable with that in control intact hippocampus $(p>0.05)$ and significantly greater than in both lesion-only hippocampus $(p<0.001)$ and hippocampus receiving CA1 cell grafts $(p<0.01)$. Values are means $\pm \mathrm{SE}$.

utable to the enlargement of interneurons because of the availability of graft-derived trophic factors.

\section{DISCUSSION}

This study provides the first evidence for the capability of specific fetal grafts to restore lesion-induced depletions in host GAD interneuron numbers within the adult CNS. By using a KA lesion model of the hippocampus, involving selective degeneration of CA3 pyramidal and dentate hilar neurons, we demonstrate that transplantation of fetal grafts containing CA3 cells into the lesioned CA3 region significantly restores lesion-induced depletions in hippocampal GAD interneuron numbers. Graft-mediated restoration of GAD interneuron numbers clearly depended on the presence of grafts containing CA3 cells, because both lesion-only hippocampus and the lesioned hippocampus receiving CA1 cell grafts did not exhibit GAD interneuron recovery.

\section{Alterations in interneuron number after intracerebroventricular KA}

Intracerebroventricular KA administration in rat, a model of TLE, exhibits hyperexcitability in both dentate gyrus and CA1 subfield after the initial degeneration of CA3 pyramidal and dentate hilar neurons (Turner and Wheal, 1991a,b; Okazaki et al., 1995; Shetty and Turner, 1996, 1997a,b; 1999a,b). Dramatic reductions in GAD-67 interneurons also occur throughout the hippocampus (Shetty and Turner, 2000). Reductions are significant in all regions at 1 month after lesion and persist at 6 months after lesion. Subclasses of interneurons also undergo significant reductions in 

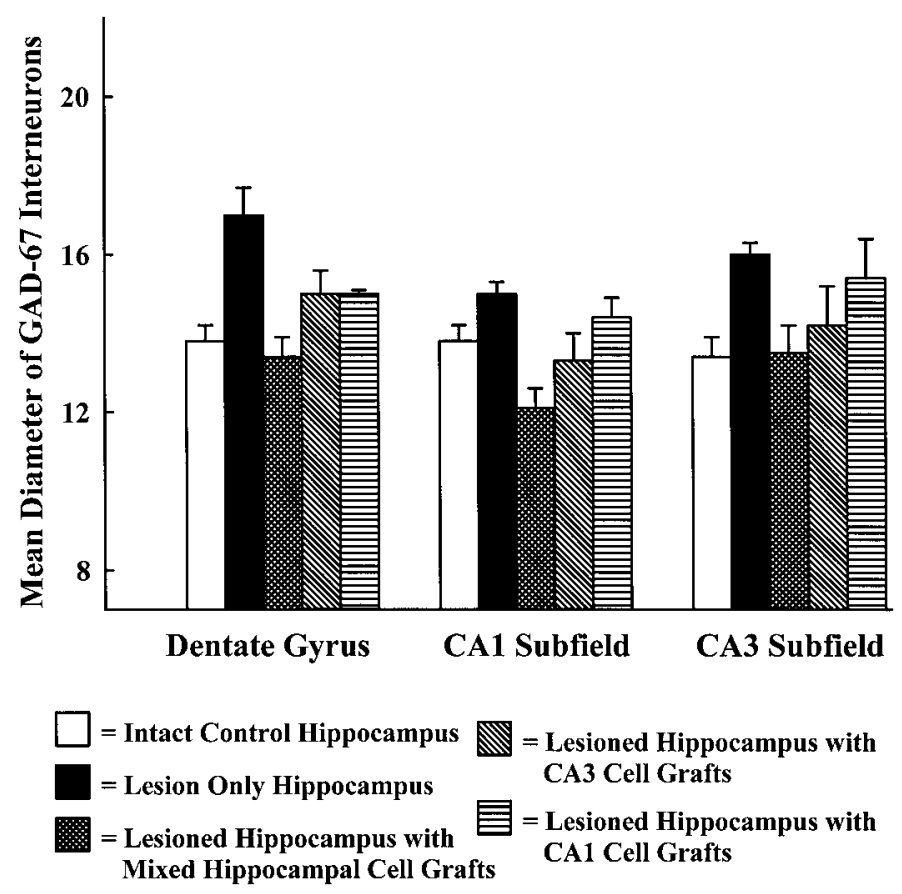

Figure 10. Histogram showing comparison of the mean diameter of soma of GAD-67-positive interneurons among intact hippocampus, lesion-only hippocampus, and lesioned hippocampus receiving different cell grafts. Note that the soma size of GAD-67 interneurons is greater in the dentate gyrus and the CA3 subfield of lesion-only hippocampus, and this increase was shown to be significant $(p<0.05)$. However, the size is comparable with that of the control intact hippocampus in the lesioned hippocampus receiving fetal grafts (mixed hippocampal, CA3, or CA1 cell grafts). Values are means $\pm \mathrm{SE}$.

number after this lesion (Sperk et al., 1986; Best et al., 1993; Shetty and Turner, 1995a). However, quantification of Nissl-stained interneurons in CA1 and CA3 subfields at 1-6 months after intracerebroventricular KA reveals no changes in interneuron density except the CA1 stratum oriens at 6 months after lesion (Shetty and Turner, 2000; our unpublished observations). Collectively, the above results underscore that reductions in GAD-67 interneuron density after intracerebroventricular KA primarily reflect downregulation of GAD expression in a major fraction of interneurons. The present results also corroborate this conclusion, because grafts containing CA3 cells into the lesioned CA3 region significantly restored hippocampal GAD interneuron density toward control levels. Thus, the structural basis of the inhibitory system remains intact after intracerebroventricular KA, particularly interneuron cell bodies and their efferent projections onto principal cells. However, there is continued loss of functional inhibition in the hippocampus after intracerebroventricular KA (Cornish and Wheal. 1989; Perez et al., 1996), suggesting that the persistent loss of GAD within interneurons may be attributable to a loss of afferent connectivity onto the interneurons and hence less activation. Additionally, other factors, particularly failure of GABA release, an activation of inhibitory autoreceptors, or a down-regulation of GABA receptors, could be involved. However, studies of direct interneuron to principal cell inhibition in KA-lesioned hippocampus have shown that this limited aspect of the inhibitory system remains primarily intact (Bernard et al., 1998).

\section{Specificity of fetal grafts on restoration of GAD-67 interneuron numbers}

The overall GAD-67 interneuron density in the lesioned hippocampus receiving either mixed hippocampal or CA3 cell grafts was comparable with that in the control hippocampus and significantly higher than in lesion-only hippocampus. Restoration was complete in the dentate gyrus and the CA1 subfield and partial in the CA3 subfield. However, the extent of restoration was variable among different hippocampal strata. There was complete recovery in the dentate hilus and the molecular layer, CA1 strata oriens and radiatum, and $\mathrm{CA} 3$ stratum radiatum. Of the remaining strata, the granule cell layer exhibited partial recovery, CA1 stratum pyramidale displayed complete restoration with CA3 cell grafting and partial restoration with mixed hippocampal cell grafting, and CA3 strata oriens and pyramidale revealed no significant recovery. Poor recovery in CA3 strata oriens and pyramidale likely reflects partial interneuron cell death in these layers because of the trauma of transplantation after KA lesion, because grafts were placed in these layers.

The GAD-67 interneuron density in the KA-lesioned hippocampus receiving CA1 cell grafts was significantly reduced compared with the control hippocampus but comparable with lesion-only hippocampus. The discrepancy between CA3 cell-containing grafts and CA1 cell grafts reflects their differential integration in the lesioned $\mathrm{CA} 3$ region. Both mixed hippocampal and CA3 cell grafts, by virtue of containing a large number of homotopic CA3 pyramidal neurons, undergo enhanced integration within the lesioned CA3 area, compared with heterotopic CA1 cell grafts (Shetty and Turner, 1995b, 1996; Zaman et al., 2000). Indeed, both mixed hippocampal and CA3 cell grafts establish significantly enhanced commissural and septal projections than CA1 cell grafts (Shetty and Turner, 1997a; Shetty et al., 2000). Furthermore, only grafts containing CA3 cells suppress aberrant mossy fiber sprouting into the dentate supragranular layer (Shetty and Turner, 1997b; our unpublished observations). Thus, restoration of GAD interneuron numbers in the lesioned hippocampus receiving grafts containing CA3 cells represents the specific effect of enhanced integration of homotopic CA3 pyramidal cells in these grafts. This is consistent with fetal homotopic transplants in other paradigms (Wictorin, 1992; Dunnett, 1995). In Parkinson's models, behavioral recovery after destruction of nigrostriatal pathway was enhanced with grafting of ventral-mesencephalic transplants into the substantia nigra rather than into their target striatum (Nikkhah et al., 1994, 1995; Starr et al., 1999). In Huntington's model, lateral ganglionic eminence (LGE) transplants (as opposed to medial ganglionic eminence transplants) into the lesioned striatum significantly improved graft-mediated behavioral recovery (Pakzaban et al., 1993). This is because the LGE is the origin of cells committed to striatal phenotypes (Deacon et al., 1994). Thus, the positive effect of fetal grafts on host recovery can be greatly enhanced with specific homotopic grafting.

\section{Potential mechanisms of restoration of GAD-67 interneuron numbers by grafts containing CA3 cells}

A loss of GAD-67 in a majority of interneurons after intracerebroventricular KA, but without involving interneuron death, is likely related to loss of both afferent input and afferent trophic support from the CA3 region, because of degeneration of the CA3 pyramidal neurons. In the intact hippocampus, CA3 pyramidal neurons provide both afferent innervation and trophic support to CA1 and CA3 interneurons (Buzsaki, 1984; Freund and Buzsaki, 1996). In addition, CA3 pyramidal neurons project to the dentate hilus, which may innervate hilar interneurons (Scharfman, 1994). Among neurotrophic factors, brain-derived neurotrophic factor (BDNF) seems to be critically required for the survival and maintenance of GAD interneurons (Jones et al., 1994; Marty et al., 1996). However, interneurons do not synthesize BDNF but depend on a constant supply from principal cells (Rocomora et al., 1996; Conner et al., 1997). Therefore, the loss of CA3 pyramidal neurons may significantly reduce both afferent innervation and BDNF supply to populations of interneurons, particularly CA1 interneurons that respond directly in a feed-forward manner to CA3 input.

Indeed, both ineffective afferent circuitry leading to interneurons and the loss of physiological competency of interneurons occur after intracerebroventricular KA (Wheal, 1989). Therefore, it is probable that reductions in both afferent innervation and afferent trophic support can trigger either decreased synthesis or a complete loss of GAD-67 protein in a sizeable fraction of interneurons 
and make them undetectable with immunostaining. In this context, the dormant basket cell hypothesis proposed by Sloviter (1991) is very relevant (Sloviter, 1991; Bernard et al., 1998). This hypothesis suggests that although interneurons survive in epilepsy models, they are hypofunctional because they have lost critical excitatory afferent inputs, and that a reversible loss of inhibition can occur in experimental tissues where most interneurons appear, at least morphologically, to be relatively normal. The hypof unctional status of interneurons in the present model is reflected by the loss of GAD-67 in a majority of interneurons. However, the persistence of GAD-67 interneuron reductions in lesion-only animals, even at 6 months after lesion, suggests that the spontaneous reorganization of circuitry that occurs after CA3 lesion (Nadler et al., 1980a,b) does not promote significant improvement in afferent innervation and afferent trophic support to interneurons. Rather, much of this reorganization is aberrant, particularly CA1 pyramidal cell and dentate granule cell axonal sprouting (Okazaki et al., 1995; Perez et al., 1996).

However, transplantation of grafts containing CA3 cells likely restores both of these critical factors by specific reinnervation of GAD-deficient interneurons, which in turn may allow for an enhanced reexpression of GAD-67 protein. Reinnervation of these interneurons may be achieved optimally by homotopic CA3 pyramidal neurons, because the presence of CA3 pyramidal neurons is the major common feature between mixed hippocampal and CA3 cell grafts, both of which produced similar restoration of interneurons. Robust projections of axons into both dentate and CA1 regions from grafts containing CA3 cells in a cross-species grafting model (Shetty and Turner, 1996, 1997a; Shetty et al., 2000; our unpublished data) reinforces the conclusion that the restoration of GAD-67 interneuron numbers reflects their reinnervation by grafted CA3 pyramidal neurons. Moreover, the other type of graft that did not restore GAD-67 interneuron numbers in this study (CA1 cell graft) has no CA3 cells and minimal axonal projections into dentate and CA1 regions. Thus, the restoration of GAD-67 interneuron numbers in the lesioned hippocampus receiving grafts containing CA3 cells is likely the result of reexpression of GAD-67 protein in interneurons, attributable principally to their reinnervation by grafted CA3 pyramidal cells.

In conclusion, restoration of GAD-67 immunolabeling in interneurons by specific fetal grafts appears valuable, because reactivation of interneurons may significantly ameliorate both loss of postsynaptic inhibition and hyperexcitability in the CA3-lesioned hippocampus. Along with other beneficial effects of grafting in the lesioned hippocampus, particularly the suppression of aberrant mossy fiber sprouting and a partial restoration of damaged circuitry (Shetty and Turner, 1996; Shetty et al., 2000), graft-mediated normalization of host GAD interneurons may provide a highly novel means for ameliorating hippocampal hyperexcitability after lesions.

\section{REFERENCES}

Abercrombie M (1946) Estimation of nuclear population from microtome sections. Anat Rec 94:239-246.

Bernard C, Esclapez M, Hirsch JC, Ben-Ari Y (1998) Interneurons are not so dormant in temporal lobe epilepsy: a critical reappraisal of the dormant basket cell hypothesis. Epilepsy Res 32:93-103.

Best N, Mitchell J, Baimbridge KG, Wheal HV (1993) Changes in parvalbumin immunoreactive neurons in the rat hippocampus following a kainic acid lesion. Neurosci Lett 155:1-6.

Buzsaki G (1984) Feed-forward inhibition in the hippocampal formation. Prog Neurobiol 22:131-153.

Conner JM, Lauterborn JC, Yan Q, Gall CM, Varon S (1997) Distribution of brain-derived neurotrophic factor (BDNF) protein and mRNA in the normal adult rat CNS: evidence for anterograde axonal transport. J Neurosci 17:2295-2313.

Cornish SM, Wheal HV (1989) Long-term loss of paired-pulse inhibition in the kainic acid-lesioned hippocampus of the rat. Neuroscience 28:563-571.

Davenport CJ, Brown WJ, Babb TL (1990) GABA-ergic neurons are spared after intrahippocampal kainate in the rat. Epilepsy Res 5:28-42. Deacon TW, Pakzaban P, Isacson O (1994) The lateral ganglionic eminence is the origin of cells committed to striatal phenotypes: neural transplantation and developmental evidence. Brain Res 668:211-219.
Dudek FE, Spitz M (1997) Hypothetical mechanisms for the cellular and neurophysiological basis of secondary epileptogenesis. Synaptic reorganization. J Clin Neurophysiol 14:90-101.

Dunnett SB (1995) Functional repair of striatal systems by neural transplants: evidence of circuit restoration. Behav Brain Res 66:133-142.

Dunnett SB, Kendall AL, Watts C, Torres EM (1997) Neuronal cell transplantation for Parkinson's and Huntington's diseases. Br Med Bull 53:757-776.

Esclapez M, Tillakaratne NJK, Kaufman DL, Tobin AJ, Houser CR (1994) Comparative localization of two forms of glutamic acid decarboxylase and their mRNAs in rat brain supports the concept of functional differences between the forms. J Neurosci 14:1834-1855.

Esclapez M, Hirsch JC, Khazipov R, Ben-Ari Y, Bernard C (1997) Operative GABAergic inhibition in hippocampal CA1 pyramidal neurons in experimental epilepsy. Proc Natl Acad Sci USA 94:12151-12156.

Franck JE, Kunkel DD, Baskin DG, Schwartzkroin PA (1988) Inhibition in kainate-lesioned hyperexcitable hippocampi: physiologic, autoradiographic and immunocytochemical observations. J Neurosci 8:1991-2002.

Freund TF, Buzsaki G (1996) Interneurons of the hippocampus. Hippocampus $6: 347-470$.

Granholm AC, Bergman H, Dudek E, Browning M (1995) Synapsin I in intraocular hippocampal transplants during maturation and aging: effects of brainstem cografts. Cell Transplant 4:3-12.

Houser CR (1991) GABA neurons in seizure disorders: a review of immunocytochemical studies. J Neurochem 16:295-308.

Houser CR, Esclapez M (1996) Vulnerability and plasticity of the GABA system in the pilocarpine model of spontaneous recurrent seizures. Epilepsy Res 26:207-218.

Isacson O, Deacon T (1997) Neural transplantation studies reveal the brain's capacity for continuous reconstruction. Trends Neurosci 20:477-482.

Jones KR, Farinas I, Backus C, Reichardt LF (1994) Targeted disruption of the BDNF gene perturbs brain and sensory development but not motor neuron development. Cell 76:989-999.

Kaufman DL, Houser CR, Tobin AJ (1991) Two forms of gamma amino butyric acid synthetic enzyme glutamate deacarboxylase have distinct intraneuronal distributions and cofactor interactions. J Neurochem $56: 720-723$

Kordower JH, Freeman TB, Chen EY, Mufson EJ, Sanberg PR, Hauser RA, Snow B, Olanow CW (1998). Fetal nigral grafts survive and mediate clinical benefit in a patient with Parkinson's disease. Move Disord 13:383-93.

Lancaster B, Wheal HV (1982) A comparative histological and electrophysiological study of some neurotoxins in the rat hippocampus. J Comp Neurol 211:105-114.

Marty SP, Carroll P, Castern AE, Staiger V, Thoenen H, Lindholm D (1996) Brain-derived neurotrophic factor promotes the differentiation of various hippocampal nonpyramidal neurons, including Cajal-Retzius cells, in organotypic slice cultures. J Neurosci 16:675-687.

Mathern GW, Babb TL, Pretorius JK, Leite JP (1995) Reactive synaptogenesis and neuron densities for neuropeptide Y, somatostatin and glutamate decarboxylase immunoreactivity in the epileptic human fascia dentata. J Neurosci 15:3990-4004.

Morin F, Beaulieu C, Lacaille J-C (1998) Selective loss of GABA neurons in area CA1 of the rat hippocampus after intraventricular kainate. Epilepsy Res 32:363-369.

Mudrick LA, Baimbridge KG (1991) Hippocampal neurons transplanted into ischemically lesioned hippocampus: anatomical assessment of survival, maturation and integration. Exp Brain Res 86:233-247.

Nadler JV, Perry BW, Gentry C, Cotman CW (1980a) Degeneration of hippocampal CA3 pyramidal cells induced by intraventricular kainic acid. J Comp Neurol 192:333-359.

Nadler JV, Perry BW, Cotman CW (1980b) Selective reinnervation of hippocampal area CA1 and the fascia dentata after destruction of CA3CA4 afferents with kainic acid. Brain Res 182:1-9.

Nikkhah G, Bentlage C, Cunningham MG, Bjorklund A (1994) Intranigral fetal dopamine grafts induce behavioral compensation in the rat Parkinson model. J Neurosci 14:3449-3461.

Nikkhah G, Cunningham MG, McKay R, Bjorklund A (1995) Dopaminergic microtransplants into the substantia nigra of neonatal rats with bilateral 6-OHDA lesions. II. Transplant-induced behavioral recovery. J Neurosci 15:3562-3570.

Obenaus A, Esclapez M, Houser CR (1993) Loss of glutamate decarboxylase mRNA-containing neurons in the rat dentate gyrus following pilocarpine-induced seizures. J Neurosci 13:4470-4485.

Okazaki MM, Evenson DA, Nadler JV (1995) Hippocampal mossy fiber sprouting and synapse formation after status epilepticus in rats: visualization after retrograde transport of biocytin. J Comp Neurol 352:515-534.

Onifer SM, Low WC (1990) Spatial memory deficit resulting from ischemia-induced damage to the hippocampus is ameliorated by intrahippocampal transplants of fetal hippocampal neurons. Prog Brain Res 82:359-66.

Palfi S, Conde F, Riche D, Brouillet E, Dautry C, Mittoux V, Chibois A, Peschanski M, Hantraye P (1998) Fetal striatal allografts reverse cognitive deficits in a primate model of Huntington disease. Nat Med 4:963-966. 
Pakzaban P, Deacon TW, Burns LH, Isacson O (1993) Increased proportion of acetylcholinesterase-rich zones and improved morphological integration in host striatum of fetal grafts derived from the lateral but not the medial ganglionic eminence. Exp Brain Res 97:13-22.

Paxinos G, Watson C (1986) The rat brain in stereotaxic coordinates. London: Academic.

Perez Y, Morin F, Beaulieu C, Lacaille J-C (1996) Axonal sprouting of CA1 pyramidal cells in hyperexcitable hippocampal slices of kainitetreated rats. Eur J Neurosci 8:736-748.

Rempe DA, Bertram EH, Williamson JM, Lothman EW (1997) Interneurons in area CA1 stratum radiatum and stratum orients remain functionally connected to excitatory synaptic input in chronically epileptic animals. J Neurophysiol 78:1504-1515.

Rocomora N, Pascual M, Acsady L, de Lecea L, Freund TF (1996) Expression of NGF and NT3 mRNAs in hippocampal interneurons innervated by the GABAergic septohippocampal pathway. J Neurosci 16:3991-4004.

Sanberg PR, Borlongan CV, Koutouzis TK, Norgren RB Jr, Cahill DW, Freeman TB (1997) Human fetal striatal transplantation in an excitotoxic lesioned model of Huntington's disease. Ann NY Acad Sci 831:452-460.

Scharfman HE (1994) Evidence from simultaneous intracellular recordings in rat hippocampal slices that area CA3 pyramidal cells innervate dentate hilar cells. J Neurophysiol 72:2167-2180.

Shetty AK, Turner DA (1995a) Intracerebroventricular kainic acid administration in adult rat alters hippocampal calbindin and nonphosphorylated filament expression. J Comp Neurol 363:581-599.

Shetty AK, Turner DA (1995b) Enhanced cell survival in fetal hippocampal suspension transplants grafted to adult rat hippocampus following kainate lesions: a three-dimensional graft reconstruction study. Neuroscience 67:561-582.

Shetty AK, Turner DA (1995c) Non-phosphorylated neurofilament protein immunoreactivity in adult and developing rat hippocampus: specificity and application in grafting studies. Brain Res 676:293-306.

Shetty AK, Turner DA (1996) Development of fetal hippocampal grafts in intact and lesioned hippocampus. Prog Neurobiol 50:593-653.

Shetty AK, Turner DA (1997a) Development of long-distance efferent projections from fetal hippocampal grafts depends upon pathway specificity and graft location in kainate-lesioned adult hippocampus. Neuroscience 76:1205-1219.

Shetty AK, Turner DA (1997b) Fetal hippocampal cells grafted to kainate-lesioned CA3 of adult hippocampus suppress aberrant supragranular sprouting of host mossy fibers. Exp Neurol 143:231-245.

Shetty AK, Turner DA (1998) Hippocampal interneurons expressing glutamic acid decarboxylase and calcium binding proteins decrease with aging in Fischer 344 rats. J Comp Neurol 394:252-269.

Shetty AK, Turner DA (1999a) Vulnerability of the dentate gyrus to aging and intracerebroventricular administration of kainic acid. Exp Neurol 158:491-503.

Shetty AK, Turner DA (1999b) Aging impairs axonal sprouting response of dentate granule cells following target loss and partial deafferentation. J Comp Neurol 414:238-254.

Shetty AK, Turner DA (1999c) Fetal hippocampal cell grafting into CA3 region of adult hippocampus following kainic acid lesion rescues hippocampal interneurons from delayed cell death. American Society for Neural Transplantation and Repair Abstracts. Exp Neurol 159:613.
Shetty AK, Turner DA (2000) Fetal hippocampal transplants containing CA3 cells restore host hippocampal glutamic acid decarboxylase (GAD)positive interneuron numbers in a rat model of temporal lobe epilepsy. Soc Neurosci Abstr 26:224.

Shetty AK, Zaman V, Turner DA (2000) Pattern of long-distance projections from fetal hippocampal field CA3 and CA1 cell grafts in lesioned CA3 of adult hippocampus follows intrinsic character of respective donor cells. Neuroscience 99:243-255.

Sloviter RS (1987) Decreased hippocampal inhibition and a selective loss of interneurons in experimental epilepsy. Science 235:73-76.

Sloviter RS (1991) Permanently altered hippocampal structure, excitability, and inhibition after experimental status epilepticus in the rat: the "dormant basket cell" hypothesis and its possible relevance to temporal lobe epilepsy. Hippocampus 1:41-66.

Sloviter RS, Dichter MA, Rachinsky TL, Dean E, Goodman JH, Sollas AL, Martin DL (1996) Basal expression and induction of glutamate decarboxylase and GABA in excitatory granule cells of the rat and monkey hippocampal dentate gyrus. J Comp Neurol 373:593-618.

Sperk G, Wieser R, Widmann R, Singer EA (1986) Kainic acid induced seizures: changes in somatostatin, substance P and neurotensin. Neuroscience 17:1117-1126.

Starr PA, Wichmann T, van Horne C, Bakay RAE (1999) Intranigral transplantation of fetal substantia nigra allograft in the hemiparkinsonian rhesus monkey. Cell Transplant 8:37-45.

Tarricone BJ, Simon JR, Li YJ, Low WC (1996) Neural grafting of cholinergic neurons in the hippocampal formation. Behav Brain Res $74: 25-44$.

Tonder N, Sorenson T, Zimmer J (1990) Grafting of fetal CA3 neurons to excitotoxic, axon-sparing lesions of the hippocampal CA3 area in adult rats. Prog Brain Res 83:391-409.

Toth K, Freund TF (1992) Calbindin D28k-containing non-pyramidal cells in the rat hippocampus: their immunoreactivity for GABA and projection to the medial septum. Neuroscience 49:793-805.

Turner DA, Wheal HV (1991a) Excitatory synaptic potentials in kainicacid denervated rat CA1 pyramidal neurons. J Neurosci 11:2786-2794.

Turner DA, Wheal HV (1991b) An overview of basic mechanisms of epilepsy and their relationship to treatment. In: Neurosurgical aspects of epilepsy (Apuzzo M, ed), pp 27-42. New York: Williams \& Wilkins.

Wheal HV (1989) Function of synapses in the CA1 region of the hippocampus: their contribution to the generation or control of epileptiform activity. Comp Biochem Physiol 93:211-220.

Wictorin K (1992) Anatomy and connectivity of intrastriatal striatal transplants. Prog Neurobiol 38:611-639.

Williamson A, Patrylo PR, Spencer DD (1999) Decrease in inhibition in dentate granule cells from patients with medial temporal lobe epilepsy. Ann Neurol 45:92-99.

Woodruff ML, Baisden RH, Whittington DL, Benson AE (1987) Embryonic hippocampal grafts ameliorate the deficit in DRL acquisition produced by hippocampectomy. Brain Res 408:97-117.

Woodruff ML, Baisden RH, Nonneman AJ (1992) Effects of transplantation of fetal hippocampal or hindbrain tissue into the brains of adult rats with hippocampal lesions on water maze acquisition. Behav Neurosci 106:39-50.

Zaman V, Turner DA, Shetty AK (2000) Survival of grafted fetal neural cells in kainic acid lesioned CA3 region of adult hippocampus depends upon cell specificity. Exp Neurol 161:535-561. 